\title{
Límites a la prohibición y autorización legal del aborto consentido en el derecho constitucional comparado
}

\section{Introducción}

El objetivo de este trabajo es ofrecer algunos antecedentes de derecho comparado para la elaboración de un marco general de análisis de los presupuestos constitucionales de la regulación legal del aborto consentido.

Para efectos del ánalisis que sigue, se entenderá por "aborto" la interrupción del embarazo de una mujer, ya sea mediante la expulsión del embrión o feto, asumiendo su muerte como resultado de ello, o mediante la muerte directa del embrión o feto anidado en el útero de la mujer. Conforme a esta definición, sólo se comete aborto, en el sentido de las normas penales, cuando se produce la muerte de un embrión o feto que se encuentra implantado en el endometrio de una mujer. ${ }^{1}$

En la legislación penal comparada del aborto se hace una distinción fundamental entre el aborto practicado sin el consentimiento de la mujer embarazada y el aborto practicado con su consentimiento. El primero es siempre punible y recibe la mayor penalidad. Por el contrario, la punibilidad del aborto consentido admite usualmente importantes excepciones, y cuando es punible, su penalidad es en todo caso inferior a la del primero.

La diferencia más obvia entre un caso y otro de aborto es la que se constata desde el punto de vista de los bienes jurídicos que son afectados por el tercero que practica el aborto con o sin el consentimiento de la mujer embarazada. Cuando se practica el aborto con el consentimiento de la mujer, no se afecta su autonomía. Por ello, no hay

* Profesor de Derecho

Penal.

Facultad de Derecho, Universidad de Chile
Esta definición del concepto de aborto es impugnada por quienes desean extender la protección penai del producto de la concepción a la etapa de su desartollo previa a su implantación. La definición también origina problemas en relación con la delimitación, en el derecho penal chileno, entre el tipo del aborto y el del homicidio, definido este último en función de la hipótesis típica del infanticidio (Art. 394 del Código Penal). Para el propósito de estas páginas, sin embargo, puede obviarse la discusión de estos dos aspectos de la definición. Pues lo que aquí interesa es el examen del estarus ante la Constitución de casos en que no se discute que la acción sea constitutiva de "causar un aborto" en el senrido de la ley penal. 
lesión antijurídica a su autonomía reproductiva ni a su integridad personal. Desde este punto de vista, uno y otro caso de aborto compartirían un común denominador de disvalor de injusto, que se encontraria en la afectación del interés en la sobrevivencia del nasciturus (cualquiera que sea su justificación), diferenciándose en que en aborto no consentido concurrirían adicionalmente otros disvalores de injusto. Por eso sería un caso más grave de aborto. En suma, entre uno y otro supuesto se daría una diferencia cuantitativa.

Semejante concepción del aborto consentido no puede, sin embargo, expresar toda la dimensión del fundamento de sus diferencias frente al aborto practicado sin el consentimiento. Para hacerlo, es necesario tomar en consideración la relación que existe entre los intereses de la mujer no sólo respecto del que practica el aborto, sino de la ley que lo prohíbe bajo amenaza de una sanción penal.

El aborto practicado con el consentimiento de la mujer es un acto de ejercicio de su autonomía. Por tanto, en él se realiza aquello que es lesionado por el aborto practicado sin el consentimiento de la mujer embarazada. Por lo mismo, la punición del aborto consentido es un acto estatal de afectación de la autonomía de la mujer. El embarazo forzado es una lesión intensa a su autonomía reproductiva y una lesión considerable de su bienestar físico y psíquico. Así pues, mientras que la punición del aborto no consentido protege intereses personalísimos fundamentales de la mujer embarazada, la punición del aborto consentido afecta esos mismos intereses fundamentales.

Sólo cuando se entiende que la ley que prohíbe penalmente consentir en un aborto lesiona un bien jurídico protegido por la ley que prohíbe penalmente causar un aborto no consentido, se advierte que entre una y otra forma de aborto existe una diferencia cualitativa. En la norma que castiga el aborto consentido no hay simplemente una expresión de la finalidad de proteger el interés en la sobrevivencia del nasciturus, sino la solución de un conflicto entre ese interés y la autonomía de la mujer, en contra de ésta. Una y otra norma tienen fines de protección contrapuestos y no acumulativos.

En este artículo, el aborto consentido es analizado en el nivel del examen de validez del ejercicio del ius puniendia su respecto. Las interrogantes relevantes en este contexto son, por ejemplo, ¿puede o debe el legislador prohibir y punir el aborto? :Debe o puede dejarlo impune, total o parcialmente? ¿Debe o puede permitirlo, total o parcialmente? La pregunta que motiva estas páginas no es, por lo tanto, cuál sea la mejor regulación del aborto consentido, sino una pregunta previa a esta cuestión de política legislativa. La cuestión consiste en determinar cuál es el margen que la Constitución deja al legislador para decidir esa otra pregunta. El propósito de este trabajo es colabotar al planteamiento de propuestas interpretativas utilizando como horizonte de referencia el derecho constitucional comparado ${ }^{2}$.

2 La incidencia sobre este aspecto de las reglas y principios dei derecho internacional, en particular del derecho internacional de los derechos humanos, no es objeto de examen en estas páginas. 
El examen de derecho comparado se restringirá a dos modelos jurisprudenciales, el modelo norteamericano y el modelo alemán. Se trata no sólo de los dos modelos más prestigiosos de control de constitucionalidad de las decisiones legislativas, sino de dos modelos cuyo examen comparativo en el caso de la regulación del aborto resulta particularmente instructivo.

Tanto la Corte Suprema Federal de los Estados Unidos de Norteamérica (en adelante "CS") como el Tribunal Constitucional Federal de la República Federal Alemana (en adelante "TC") han tenido que pronunciarse sobre repetidos intentos legislativos de resolver en uno y otro sentido la regulación penal del aborto. En un principio, estos tribunales adoptaron tesis constitucionales totalmente contrapuestas. La CS sostuvo que la Constitución impedía penalizar totalmente el aborto consentido por la mujer embarazada, y el TCF sostuvo que la Constitución impedía despenalizar totalmente el aborto consentido por la mujer embarazada. Al cabo de veinte años, y sin abandonar las premisas esenciales de su decisión original, ambos tribunales han venido a encontrarse en un mismo punto: la admisión de la constitucionalidad del modelo del plazo con consejo forzoso ${ }^{3}$. Este es, sin duda, el hecho más importante del derecho comparado en materia de la regulación del aborto consentido.

Esta coincidencia no debe, sin embargo, inducir al error de considerar que la CS y el TC hayan adoptado una misma tesis interpretativa del alcance de la Constitución respecto de la punición del aborto consentido.

En la jurisprudencia de la CS la pregunta constitucional es si el legislador puede prohibir el aborto consentido. En la jurisprudencia del TC, en cambio, la pregunta es si el legislador puede permitir o no punir el aborto consentido. En la jurisprudencia de la CS el derecho constitucional que está en juego es la autonomía reproductiva de la mujer embarazada, y lo que se evalúa como constitucional es la restricción de su ejercicio mediante la punición u otra forma de obstaculización del aborto. En la jurisprudencia del TC, en cambio, el bien jurídico constitucional crucial es la vida del nasciturus, y lo que se evalúa es su desprotección como efecto de la despenalización o permisión del aborto.

Lo que sucede es que tanto desde una perspectiva como desde la otra se ha coincidido en estimar que el modelo del plazo con consejo forzoso satisface las exigencias constitucionales. La CS estima que no restringe el ejercicio de la autonomía reproductiva de la mujer embarazada de modo constitucionalmente inadmisible, y el TC, que no deja al nasciturus desprotegido de modo constitucionalmente inadmisible.

3 En lo esencial, se trata de una regla que permite o al menos no sanciona el aborto consentido por la mujer embarazada que es practicado dentro del primer trimestre y bajo la condición (entre otras) de sometetse la mujer a una entrevista, cuya finalidad comprende incluso la presentación a la mujer de argumentos para disuadirla de su propósito de abortar. 


\section{La Constitución como límite a la penalización del aborto consentido: la jurisprudencia de la Corte Suprema Federal de los Estados Unidos de Norteamérica ${ }^{4}$}

\subsection{La posición originaria.}

El caso central es Roe $v$. Wade, ${ }^{5}$ en el cual se declara la inconstitucionalidad de la ley penal del Estado de Texas, por restringir la autorización legal del aborto consentido exclusivamente al caso del aborto terapéutico, es decir, el practicado para evitar un peligro para la vida o la salud de la mujer.

La decisión de la CS descansa fundamentalmente en el precedente de Griswold v. Connecticut. ${ }^{6}$ En este otro caso, la CS reconoció un derecho de privacidad (privacy) a parejas casadas respecto de su relación marital, incluyendo la adopción de decisiones acerca de su vida reproductiva. ${ }^{7}$ La fundamentación de ese derecho que se hace en el voto de mayoría, redactado por el Juez Douglas, es escueta y no particularmente precisa. El voto constata que la CS ha reconocido en su jurisprudencia derechos no consagrados expresamente en el texto, que los casos demuestran que las garantías constitucionales tienen "penumbras", y que en algunas garantías ello se concreta en "zonas de intimidad". Y luego, mediante un argumento a fortiori, sostiene que el reconocimiento previo de varios derechos de penumbra a "privacidad y reposo" obliga a reconocer a la relación marital una zona de privacidad protegida por la Constitu-

4 En general, sobre el debate acerca del aborto en la cultura juridica norteamericana, vid. John Hart Ely, The Wages of the Crying Wolf: A Comment on Roe v Wade, en: Yale Law Journal, Vol. 82 (1973), págs. 920-949; Mary Ann Glendon, Abortion and Divorce in Western Law, Cambridge (Ma.), 1987, págs. 10-62 ; Laurence Tribe, Abortion: The Clash of Absolutes, New York, 1991; Ronald Dworkin, Lifés Dominion, New York, 1993, págs. 1-178; el mismo: Freedom's Law, Cambridge (Ma), 1996, págs. 39-129. Para un vistazo acerca de las cuestiones actualmente más conflictivas, Jean Reith Schroedel, Pamela Fiber, Bruce D. Snyder, Women's Rights and Fetal Personhood in Criminal Law, en: Duke Journal of Gender Law \& Policy Vol. 7 (2000), págs. 89 y ss.; Michael Stokes Paulsen, Abrogating Stare Decisis by Statute: May Congress Remove the Precedential Effect of Roe and Casey?, en: Yale Law Journal Vol. 109 (2000), págs. 1535 y ss.; David B. Cruz, "The Sexual Freedom Casesw? Contraception, Abortion, Abstinence, and the Constitution, en: Harvard Civil Rights-Civil Liberties Law Review Vol. 35 (2000), págs. 299 y ss.; Martin H. Belsky, Privacy: The Rehnquist Court's Unmentionable "Right", en: Tulsa Law Review, Vol. 36 (2000), págs. 43 y ss.

5410 L.S. 113 (1973), sentencia de 22 de enero. Se trata de una opinión de mayotía, con disidencias de los jueces White y Rehnquist. Junto con este caso fue decidido Doe v. Bolton, 410 U.S. 179 (1973). En esta decisión la CS afrmó que la regulación que permite el aborto practicado por un médico a condición de que éste lo juzgue necesario, usando su "mejor juicio clf́nico", no es inconstitucional, pero que si lo es restringir los abortos permitidos a aquellos practicados en hospitales.

6381 U.S. 479 (1965), opinión de mayoría, con disidencias de las Jueces Black y Stewart.

7 En tal virtud, la CS deciaró inconstitucional disposiciones legales del Estado de Connecticut que sancionaban con multa o prisión de sesenta días a un año a quien usase una droga, un artículo médico o un instrumento con el propósito de prevenir la concepción; esta sanción se hacla adernás exrensible a cualquiera que asistiere, ayudare, aconsejare, causare, empleare u ordenare la comisión del hecho. Los apelantes eran médicos que prestaban asesoria profesional a parejas para la planificación de su vida reproductiva.

8 Las consideraciones del voto provienen básicamente de las consideraciones de los votos disidentes del propio Juez Douglas y el juez Harlan en Poe v. Ullmann, 367 U.S. 497 (1961), 509.555. 
ción. ' Con posterioridad, y en un caso muy cercano al que aquí interesa, Eisenstadt $v$. Baird ${ }^{10}$ la CS deciaró inconstitucional una norma del Estado de Massachusetts que prohibía la entrega de anticonceptivos salvo por la prescripción médica a parejas casadas, extendiendo así el holding de Griswold a personas solteras. Con esta decisión, la CS universalizó el derecho a la privacidad, bajo la cláusula de igual protección, deciarándolo un derecho individual. ${ }^{11}$

La opinión de mayoría de la CS en Roe v. Wade, redactada por el Juez Blackmun, comienza por constatar que la represión penal del aborto, sin diferencias según el estado de desarrollo del feto, es de reciente data en los Estados Unidos. Hasta bien entrado el Siglo XIX -sostiene la Corte-, la postura tradicional consistía en distinguir entre el aborto cometido con anterioridad y con posterioridad de los primeros signos de movimiento del feto en el útero (quickening). Esto le permite concluir que el horizonte normativo a la época de la adopción de la Constitución era más liberal y permisivo para la mujer embarazada que la regulación estándar de mediados del Siglo XX. ${ }^{12}$ Junto con ello, la CS observa la tendencia reciente -a la época del fallo- a una liberalización de esa regulación, y su aceptación en organizaciones de las profesiones médica y jurídica. ${ }^{13} \mathrm{La}$ CS luego constata que existen tres causas principales que explicarían la prohibición absoluta del aborto: (a) el interés en desincentivar la sexualidad, (b) el interés en impedir intervenciones riesgosas para la mujer, y (c) el interés en proteger la vida del embrión o feto. La primera causa no tiene valor como justificación de la regulación. Las otras dos causas pueden valer como razones justificatorias, pero deben ser ponderadas con el derecho a la autonomía reproductiva de la mujer embarazada. ${ }^{14}$

Este planteamiento es la médula de la decisión de la CS. Por una parte, reconoce el estatus de derecho constitucional del interés de autonomía reproductiva de la mujer embarazada, como parte de su derecho constitucional a la privacidad. ${ }^{15}$ Pero por otra parte niega el carácter absoluto o no cualificado de este derecho, admitiendo la posible justificación de su restricción en función de la protección de un interés estatal apremiante (compelling interest). ${ }^{16}$ Estos intereses equiparables son, como se ha visto, la salud de la mujer embarazada y la vida del nasciturus. Este planteamiento es formu-

9 La sentencia contiene votos concurrentes cuya mayor preocupación se centra en cuestiones de la doctrina de la incorporación, es decir, el uso del derecho al debido proceso oponible a los poderes de los Estados federados (Enmienda XIV) como fundamento del reconocimiento de la oponibilidad a los Estados federados de derechos que la Constitución federal explíciramente sólo consagra frente a los poderes federales.

I0 405 L.S. 438 (1972), opinión de mayoría, redactada por el Juč Brennan, con disidencia del Juez. Burger.

11405 U.S. $438,452-455(1972)$.

12410 U.S. $113,140-141$ (:973).

13 Cit. supra, en las págs. 142-147.

$14 \mathrm{Id}$, en las págs. $148-152$.

15 ld. en ias págs. $152-153$.

16 Id. en las págs., 153-156. El término "compelling interest" es técnico: designa un interés con un peso especffico cualificado, por oposición a un interés legitimo cualesquiera. Este último es suficiente para justificar la afectación de un interés general de libertad, conforme a la doctrina del derecho al debido proceso sustantivo; para justificar la afectación de un derecho fundamental especifico, como la privacidad, la misma doctrina requiere un interés apremiante. 
lado por la CS como un rasgo distintivo del aborto frente a otras formas de ejercicio de la autonomía reproductiva o sexual. ${ }^{17}$

Respecto de la salud de la mujer, la opinión de la CS es que su protección adquiere el carácter de interés apremiante cuando el riesgo de la práctica del aborto supera el margen de riesgo inherente al parto. A la luz de la evidencia médica, la CS determina que el paso del primer al segundo trimestre del embarazo es el momento en el que este interés adquiere su peso específico cualificado. ${ }^{18}$ Más difícil es la ponderación del peso específico de la vida del nasciturus como interés protegido. Por una parte, la CS niega que el nasciturus sea calificable como "persona" en el sentido de la Constitución, deduciendo de ello que que su vida no está protegida constitucionalmente. ${ }^{19}$ Por otra parte sin embargo, acepta que el interés de un Estado en proteger la vida del nasciturus puede adquirir el peso específico de un interés apremiante. Eso sí, la CS constata la pluralidad de puntos de vista acerca del comienzo de la existencia de la vida humana, y por tal razón niega que un Estado pueda atribuirle ese peso específico desde el instante mismo de la concepción. En su lugar, la CS adopta el criterio menos discutible en el contexto de esa pluralidad de opiniones; a su juicio, el interés en proteger la vida del nasciturus se vuelve apremiante con el paso del segundo al tercer trimestre del embarazo, que marca por regla general la adquisición por el feto de la capacidad de vivir extrauterinamente (viabilidad) ${ }^{20}$

Efectuadas estas consideraciones, el resultado de la ponderación de intereses en conflictos es la "regla de los trimestres". Conforme a esta regla, antes de terminar el primer trimestre del embarazo, el Estado no puede restringir el derecho de la mujer a poner término a su embarazo mediante la práctica de un aborto: la decisión debe quedar entregada a la mujer, en su relación de paciente con el médico que practica el aborto. Durante el segundo trimestre, el Estado puede intervenir regulando la práctica del aborto, cuando ello sea necesario en función de la protección de la salud y la vida de la mujer embarazada. A partir del inicio del tercer trimestre, el Estado puede incluso prohibir el aborto consentido para proteger la vida del nasciturus, salvo en los casos en que, según el diagnóstico médico, el aborto sea necesario para la preservación de la salud o la vida de la madre. ${ }^{21}$

Considerado en su propio contexto, Roe $v$. Wade es, pues, un intento de hacer un balance entre intereses en conflicto, reconociendo a cada uno un campo de predomi.

17 Id., en la pág. 159.

I $8 \mathrm{ld}$, en la pág. 163.

19 ld., en las págs. 156-159. Las razones de la CS son sistemáticas (no hay disposicion alguna en que la Consti:i. ción use el término "persona" en un sentido que manifiestamente incluya a no nacidos y en la gran mavoria de los casos manifiestamente los excluye; asimismo la regulación penal demuestra la desigualdad valoraciva funciamental entre la muerte de un feto y la muerte de un nacido) e históricas (el trato diferenciado es inmemorial. el horizonte normativo a la época del establecimiento de la Constitución implicaba diferenciacioncs aún más pro-
fundas).

20 ld. en las págs. 159-162.

21 Id. en las págs. 164-166. 
nio sobre el otro. La única diferencia está en que el predominio del derecho a la autonomía reproductiva en el primer trimestre no reconoce excepciones, mientras que el predominio de la vida del nasciturus en el tercer trimestre encuentra su límite en el peligro para la salud o la vida de la mujer embarazada.

\subsection{La evolución posterior.}

La consecuencia práctica de la decisión de la CS fue la declaración de inconstitucionalidad de la gran mayoría de la legislación estatal relativa al aborto. Frente a esa restricción del ámbito discrecional de decisión de la política legislativa estatal, los gobiernos estatales conservadores comenzaron a desarrollar una política de desafío de la CS. La jurisprudencia de las casi dos décadas que separa a Roe v. Wade de Planned Parenthood of Southeastern Pennsylvania $v$. Casey, ${ }^{22}$ que define la nueva posición de la CS, es un intrincado tejido de distinciones elaboradas para justificar qué clase de restricción estatal al derecho a abortar era compatible o incompatible con la Constitución. Este desarrollo jurisprudencial sufrió un dramático giro en su etapa inmediatamente anterior a Casey, con Webster v. Reproductive Health Services. ${ }^{23}$

Durante un período de dieciséis años se mantuvo el predominio de los Jueces de la CS que apoyaron Roe $v$. Wade. Aplicando este precedente, la CS declaró inconstitucional (a) utilizar lenguaje impreciso al distinguir entre la viabilidad y la no viabilidad del feto, ${ }^{24}$ (b) subordinar en términos absolutos la exención de pena de la mujer casada a la autorización de su marido, ${ }^{25}$ así como (c) la exención de pena de la mujer menor de edad a la autorización de sus padres, ${ }^{26}$ (d) prever una autorización judicial en subsidio de la autorización de los padres para la cual no basta con acreditar la madurez de la muchacha y el hecho de estar informada, sino que se requiere demostrar la conveniencia médica del aborto, ${ }^{27}$ (e) prever una autorización judicial respecto de la cual se omite indicar que su propósito es verificar la madurez e información de la muchacha, ${ }^{28}$ (f) prohibir métodos abortivos sin que ello se encuentre razonablemente relacionado con la protección de la salud de la mujer, ${ }^{29}$ (g) exigir que el aborto sea practicado en hospitales ${ }^{30}$ o (h) exigir que lo sea en centros de cuidado intensivo, ${ }^{3:}$ (i) imponer al médico el deber de dar información a la mujer no relacionada razonablemente con las consecuencias del aborto para su salud, ${ }^{32}$ (j) exigir la espera de un plazo

22505 L.S. 833 (1992).

23492 L.S. 490 (I989).

24 Planned Parenthood of Central Missouri et. al. v. Danforth, 428 L.S. 52 (I976), Colautti v. Franklin, 439 L.S. 379 (1979).

25 Planned Parenthood of Central Missouri et. al. v. Danforth, 428 L.S. 52 (1976).

26 Cit. supra, nora anterior.

27 Bellotri v. Baird, 433 U.S. 622 (1979).

28 City of Akron v. Akron Center for Reproductive Health, Inc., 462 U.5. 416 (1983) (para el segundo trimestre).

29) Planned Parenthood of Central Missouri et, al. v. Danforth, 428 U.S. 52 (1976) (amniocentesis salina),

30 City of Akron v. Akron Center for Reproductive Health, Inc., 462 U.S. 416 (1983) (para el segundo trimestre).

31 Planned Parenthood Association of Kansas City, Missouri Inc. v. Ashcroft, 462 L.S. 476 (1983).

32 City of Akton v. Akron Center for Reproductive Health, Inc., 462 L.S. 416 (1983) (para el segundo :rimestre), Thornburgh v. American College of Obstetricians and Gynecologists, 476 L'S. 747 (1986) 
entre el otorgamiento del consentimiento de la mujer y la práctica del aborto ${ }^{33} \mathrm{y}(\mathrm{k})$ hacer públicos los registros y los informes de las instituciones que practican abortos. ${ }^{34}$

Con todo, durante esta misma fase de desarrollo de su jurisprudencia la CS declaró que no era inconstitucional bajo Roe $v$. Wade (a) prohibir absolutamente el aborto practicado por personas que no son médicos, ${ }^{35}$ (b) exigir un diagnóstico médico de no viabilidad del feto en el caso concreto, ${ }^{36}$ (c) exigir a la mujer una declaración escrita donde conste el carácter libre e informado de su consentimiento, ${ }^{37}$ (d) imponer a las instituciones en las que se practican abortos deberes de mantención de registros y de información, ${ }^{38}$ (e) restringir el otorgamiento de subsidios a casos excepcionales de aborto consentido (aborto terapéutico), ${ }^{39}$ (f) exigir para el otorgamiento excepcional de subsidios las opiniones concurrentes de dos médicos, ${ }^{40}(\mathrm{~g})$ subordinar la exención de pena de la mujer menor de edad a la autorización de sus padres, siempre y cuando pueda obtenerse en su defecto autorización judicial, ${ }^{41}$ (h) exigir a la mujer menor de edad que notifique a sus padres de su decisión de abortar, siempre y cuando se cumpla con el requisito adicional recién expuesto, ${ }^{42}$ (i) exigir que los abortos sean practicados en clínicas que cuenten con una licencia, ${ }^{43}$ (j) exigir la concurrencia de dos médicos para la práctica de abortos durante el tercer trimestre, siempre que se reconozca una excepción para casos de urgencia ${ }^{44} \mathrm{y}(\mathrm{k})$ exigir la elaboración de un informe acerca de la patología sufrida en casos de abortos durante el tercer trimestre. ${ }^{45}$.

En los últimos casos de este desarrollo jurisprudencial es perceptible en la CS una nueva opinión de minoría, sustentada por la Juez O'Connor, que sostenía la necesidad de reinterpretar la jurisprudencia en el sentido de una sustitución de la rígida regla de los trimestres por un criterio más flexible de evaluación de la inadmisibilidad de las restricciones impuestas al ejercicio del derecho a abortar. ${ }^{46}$ El punto crítico de

33 City of Akron v. Akron Center for Reproductive Health, Inc., 462 U.S. 416 (1983). Este caso decidió también que era inconstitucional, por violación del debido proceso, ordenar vagamente que los testos fetales fueran tratados en forma "humana".

34 Thomburgh v. American Coilege of Obstetricians and Gynecologists, 476 U.S. 747 (1986).

35 Connecticut v. Menillo, 423 L'S. 9 (1975).

36 Planned Parenthood of Central Missouri et. al. v. Danforth, 428 L.S. 52 (1976).

37 Cit. supra, nota anterior.

38 Ibidem.

39 Beai v. Doe, 432 U.S. 438 (1977), Maher v. Roe, 432 U.S. 464 (1977), Poelcker v. Doe, 432 U.S. 519 (1977); Harris v. McRae, 448 L.S. 398 (1980), Williams v. Zbaraz, 448 L.S. 358 (1981).

40 Beal v. Doe, 432 L.S. 438 (1977).

41 Belloti v. Baird, 428 L.S. 132 (1976) (Belotti l); Bellotti v. Baird, 433 U.S. 622 (1979) (Belotti II); Planned Parenthood Association of Kansas City, Missouri Inc. v. Ashcroft, 462 L'S. 476 (1983).

42 H.L. v. Matheson v. Governor of Ltah, 450 U.S. 398 (1981)

43 Simopoulos v. Virginia, 462 L.S. 506 (1982)

44 Planned Parenthood Associarion of Kansas City, Missouri Inc. v. Asheroft, 462 U.S. 476 (1983); Thomburgh v. American College of Obstetricians and Gynecologisrs, 476 U.S. 747 (1986).

45 Cit. supra, nota anterior.

46 City of Akron v. Akron Center for Reproductive Health, Inc., 462 U.S. 416, 452.474 (1983); Planned Parenthood Association of Kansas City, Missouri Inc. v. Ashcroft, 462 U.S. 476, 505 (1983); Thornburgh v. American College of Obstetricians and Gynecologists, 476 L.S. 747, 814-833 (1986). 
la rigidez de Roe $v$. Wade considerada inaceptable por esta opinión se encontraba en la prohibición al Estado de expresar regulativamente su interés en la protección la vida del nasciturus antes de su viabilidad. Este es precisamente el punto crucial de Webster v. Reproductive Health Services. ${ }^{4}$ ?

$\mathrm{Al}$ momento de resolverse Webster, en virtud de nuevas designaciones de jueces, la otrora minoría contraria a Roe v. Wade ya podía formar mayoría en la CS. ${ }^{48}$ En este caso se impugnaba la constitucionalidad de una regulación de Missouri que en su preámbulo afirmaba que la vida del nasciturus comienza con la concepción y deducía de ello la necesidad de reconocerle ampliamente derechos y otorgarle amplia protección, que además prohibía el uso de instalaciones públicas para la práctica de cualquier aborto que no se hiciera en razón de salvar la vida de la mujer, y que obligaba a la mujer que tuviera razón para creer que tenía un embarazo de más de veinte semanas y a su médico a practicar acciones diligentes de determinación de la viabilidad del feto. La opinión de pluralidad, redactada por el Juez (ahora Presidente) Rehnquist, sostuvo que el preámbulo no tenía un efecto jurídico concreto, y que las normas restrictivas no eran inconstitucionales. Como se ha dicho, la cuestión crucial consistía en este caso en la justificación de la constitucionalidad de las restricciones basadas en la posible viabilidad del feto, que contrariamente a la regia trimestral era operativa en el segundo trimestre del embarazo. En este punto, la opinión de la nueva mayoría de la CS se dividió. Los Jueces Rehnquist, White, Kennedy y Scalia sostuvieron que el caso exigía revocar la regla de los trimestres y reformular el estatus constitucional de la autonomía reproductiva de la mujer. ${ }^{49}$ La Juez O'Connor rechazó esta tesis, señalando que esa revocación y reformulación no era necesaria para justificar la constitucionalidad del examen de viabilidad, pues a su juicio éste no era inconsistente con la regla del trimestre. ${ }^{50}$ Así pues, el examen de Roe $v$. Wade por la nueva mayoría de la CS quedó pospuesto. Tal como la opinión disidente de Webster lo hizo ver, esta decisión producía la consecuencia francamente anómala de invitar a los Estados a desafiar abiertamente el derecho constitucional reconocido no obstante por la propia CS como vigente, acerca de una de las cuestiones más polémicas para la sociedad civil norteamericana. ${ }^{51}$

En el caso siguiente, Hodgson v. Minnesota ${ }^{52}$ se produce la peculiar situación de que el voto de la Juez O'Connor concurre con el de los defensores de Roe $v$. Wade a su man-

47492 U.S. 490 (1989).

48 Las designaciones de los Jueces Scalia y Kennedy habian colocado en una posición de control a la fracción formada por los Jueces White, Rehnquist y O'Connor. Por su parte, la minoria la formaba ahora el grupo de los viejos defensores de Roe $v$. Wade, los Jueces Blackmun, Brennan, Marshall y Srevens.

$49 \mathrm{Idem}$, en las págs. 513-521. La tesis consistía en calificar el detecho de la mujer a practicar un aborto como un interés general de libertad, con la consecuencia de que la restricción de su ejercicio es legftima con tal que se justifique razonablemente como medio adecuado para lograr un fin legitimo (vid. supra, nota 25).

50 Idem, en las págs. 525-532. Vid. la enérgica protesta del Juez Scalia contra esta opinión (idem, en las págs. 533 537.

51 ldem, en la pág. 538.

52497 U.S. 417 (1990). 
tención como derecho vigente, aunque con su propia concepción del precedente, y a la vez concurre con el voto de los adversarios de Roe $v$. Wade en la validación de la constitucionalidad de todas las restricciones impuestas por el Estado de Minnesota a la práctica de un aborto por una mujer menor de edad, consistentes en el deber de notificar a ambos padres, con la posibilidad de la autorización judicial subsidiaria, y el deber de someterse a un plazo de espera de cuarenta y ocho horas desde la notificación antes del aborto. Con esta incierta situación 4-1-4 se cierra la etapa del desarrollo de la jurisprudencia de la CS en materia de aborto bajo el entendimiento originario de Roe $v$. Wade.

\subsection{La situación actual.}

Al plantearse Planned Parenthood of Southeastern Pennsylvania v. Casey. ${ }^{55}$ la composición de la CS había nucvamente cambiado, con la sustitución de los Jueces Brennan y Marshall por los Jueces'Thompson y Souter, designados por el entonces Presidente George Bush. Con ello, la fuerza del apoyo a Roe $v$. Wade y la base para cl voto mediador de la Juez O'Connor habia desaparecido. La sorpresa del caso fue que la Juez O'Connor logró el voto de otros dos Jucces (Kennedy y Souter), para formar una opinión que en los puntos más importantes contó con el respaldo (parcial) de los Jueces Blackmun y Stevens, los últimos sobrevivientes favorables a Roe v. Wade, quedando en estos puntos en minoría y como disidencia la posición más adversa a Roe $v$. Wade. En lo esencial, esto significó quc la CS mantuvo el reconocimiento de un derecho constitucional de la mujer a practicar un aborto y el desconocimiento de un derecho constitucional del nasciturus a la vida.

La controversia recayó sobre la constitucionalidad de una regulación de Pennsylvania establecida en 1988 y 1989 , que imponía como restricciones (a) el deber de la mujer a recibir información acerca del aborto y esperar a lo menos veinticuatro horas para su práctica, (b) el deber de una mujer menor de edad de obtener el consentimiento de uno de sus padres, o una autorización judicial en subsidio, (b) el deber de una mujer casada de firmar una declaración indicando que ha notificado a su cónyuge y (d) el deber de las instituciones que practican abortos de mantener registros y efectuar in-

53 Cabe seriáar que también al incer:or del sector de los defennores die hoe $\nu$. Wade se produce en este caso una

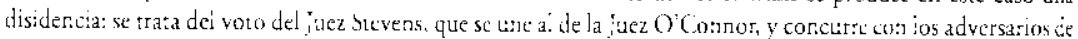
Roe $v$. Wade er é resultacio de aceptar a constiacionalidad ici piazo de 48 inoras. Fsta complicada situación de corcestores reciprocas sobre la base de sofssicadas discinciones es descrita con mordaz precisión por el Jïez Scalia en su opinión parciaimente disidente (cit supra, noia anterior, en as págs. 479-480).

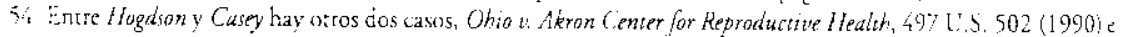
Irving Rust v. Sullivan, 500 L.S. 173 (1991). que no representar. un desarroilo jurisprudencial ere esta materia. ¿l

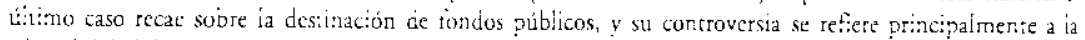

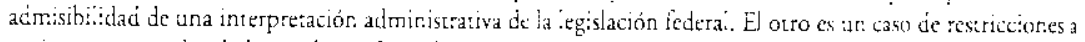
mujeres menores de edac, resuciso en favor de su cunst:tucionalidad mediante áa ap'icación de ins precéentes de

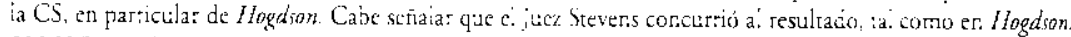

55505 Z.S. 833 (1992), sentencia cie 29 imio.

56 Formada por los Jueces Rehrectisi, White, Scáia y I'loortas. 
formes, manteniendo en reserva la identidad de las mujeres pero incluyendo el deber de informar la omisión de notificación de la mujer casada a su cónyuge. Las tres primeras restricciones no eran aplicables en caso de un aborto de emergencia.

La CS declaró que las exigencias de información, plazo de espera, consentimiento paterno (con autorización judicial subsidiaria), así como el deber de mantener registros y efectuar informes, no eran inconstitucionales. Pero al mismo tiempo declaró inconstitucional el deber de informar la omisión de notificación al cónyuge. Este último punto es consecuencia de la decisión de mantener el precedente de Roe $v$. Wade, que es el aspecto crucial de Casey.

La consideración de Roe $v$. Wade como precedente vinculante y por lo tanto de su bolding como derecho constitucional vigente tiene lugar sin embargo desde distintas perspectivas. El holding de Roe $v$. Wade es definido en Casey como el principio de que la mujer tiene el derecho de decidir el término de su embarazo mediante un aborto antes de que el feto sea viable. El Juez Blackmun sostuvo que la mantención de este bolding exigía mantener también la regla de los trimestres, y que bajo esa regla todas las restricciones impuestas por la regulación de Pennsylvania eran inconstitucionales. El Juez Stevens coincidió en considerar inconstitucionales todas las restricciones, salvo por la de mantener registros y efectuar informes. Los Jueces O'Connor, Kennedy y Souter, en cambio, dieron al holding de Roe v. Wade una nueva formulación, y sobre la base de esa nueva formulación aceptaron la constitucionalidad de todas las restricciones legales discutidas en el caso, salvo las relacionadas con la notificación al cónyuge.

Esta ratificación de Roe $v$. Wade tiene particular interés para la teoría de la adjudicación constitucional, ya que se relaciona con el peso argumentativo de la institución del precedente dentro y fuera del marco de la doctrina del stare decisis, y con una concepción constructivista de la interpretación de la Constitución. ${ }^{57}$ Para el examen de derecho constitucional comparado es de particular importancia la fundamentación del derecho al aborto como expresión de un principio de inexigibilidad del embarazo y la maternidad. Conforme a la opinión de la Juez O'Connor, el derecho de libertad de la mujer se basa en el carácter único de la maternidad: los efectos físicos y psíquicos del embarazo pueden implicar para ella un sufrimiento demasiado íntimo y personal como para que el Estado se encuentre legitimado para imponerle, sin más, un deber basado en una determinada concepción del rol de la mujer. La condición de la mujer requiere una limitación de estas exigencias para que ella sea libre en la configuración de sus imperativos espirituales y su puesto en la sociedad. En este sentido es que, a pesar de todas las diferencias que puedan existir entre el control de la concepción y el aborto, una y otra decisión comparten un mismo carácter en ciertos aspectos críticos.

57 Cit. supra, nota precedente, págs. 853-869. Este es el aspecto de la sentencia más destacado por Ronald Dworkin (al respecto, Roe was saved, en: Freedom' Law, cit. supra, nota, págs. 117-129; también de interés por su relación con la disputa en torno a la mecodologfa de interpretación constitucional, What Bork's defeat meant, en: op. cit., págs. 276-286). 
Por eso es que el derecho a la privacidad reconocido en Griswold y Eisendtadt cubre también el aborto. ${ }^{58}$

El reconocimiento de este derecho con un ámbito irreductible de decisión autónoma de la mujer hace inconstitucional la prohibición estatal del aborto consentido antes de la viabilidad del feto. Este es el otro aspecto central del holding de Roe v. Wade. Aparte del respeto por el precedente, las razones del voto de la Juez O'Connor para mantener este holding son básicamente dos. En primer lugar, que el hecho de que en su estadio final de desarrollo la condición intrauterina o extrauterina de la vida del feto sea algo contingente, es decir, de que exista una posibilidad realista de que ese feto nazca, sobreviva y desarrolle una vida independiente, permite con justicia y razonabilidad asignar un peso tal al interés en proteger la vida del feto que tenga una clara preponderancia frente a la autonomía de la mujer. Por lo demás, no hay un criterio alternativo más operativo para fundamentar algún otro punto en el embarazo en el cual el peso de la autonomía de la mujer sea superado por el peso de la vida del embrión o feto. En segundo término, la solución de la viabilidad tiene en su favor un elemento de fairness en relación con la omisión de la mujer de practicarse un aborto. Pues en términos amplios puede decirse que la mujer que deja desarrollarse el feto hasta el punto de su viabilidad en cierto sentido ha renunciado al ejercicio de ese derecho en beneficio del interés del Estado en proteger al feto. ${ }^{59}$ Todo lo dicho presupone, como siempre, que el interés en la preservación de la vida del feto tiene un estatus infraconstitucional..$^{60}$

Tanto o más importantes que los argumentos para respaldar el holding de Roe v. Wade son los cambios que Casey introduce en el margen de admisibilidad de la intervención del Estado en la decisión de la mujer embarazada. En lo esencial, el cambio consiste en el abandono de la regla de los trimestres, y su sustitución por el nuevo test más flexible de constitucionalidad, basado en la noción de "carga indebida" (undue burden), que había sido propuesto anteriormente en los votos disidentes o parcialmente concurrentes de la Juez O'Connor. ${ }^{61}$

Conforme estos nuevos estándares, es constitucionalmente incorrecto derivar del reconocimiento del derecho al aborto un derecho a su práctica en aislamiento o sin interferencia alguna del Estado como mínimo dentro de los primeros tres meses. A juicio de la opinión de la Juez O'Connor no hay base alguna en Roe $v$. Wade ni en la mayor parte de la jurisprudencia que lo sigue para negar la legitimidad del interés del Estado en promover $y$ proteger la vida de embriones y fetos aún no viables, aunque no tenga tanto peso como el derecho constitucional de la mujer a abortar, es sin embargo un interés legítimo. Es claro que ese interés puede expresarse en el estableci-

58 Cit. supra, nota 67, paig. 852.

$59 \mathrm{Idem}$, en las págs. 869-871.

60 Al respecto, vid. la opinión en pare concurrente del Juez Stevens, idem, págs. 912-914.

6. Supra, nota 55 . 
miento de procedimientos o programas que tengan el efecto de incrementar el costo o disminuir la accesibilidad de las prestaciones médicas para la práctica del aborto. Por ello debe reconocerse que ese interés puede expresarse también legítimamente en la configuración de un marco razonable para la práctica del aborto, dentro del cual incluso se le haga presente a la mujer que hay buenos argumentos en favor de mantener el embarazo y se le informe acerca de las posibilidades accesibles a asistencia para su embarazo y maternidad. ${ }^{62}$

Así reconstruido el holding de Roe $v$ Wade, la cuestión constitucional consiste en enunciar algún criterio que permita distinguir, para cualquier momento del embarazo previo a la viabilidad del feto, entre las regulaciones o restricciones admisibles y las inadmisibles. Ese criterio lo encuentra la opinión de la Juez $\mathrm{O}^{\prime}$ Connor en cl concepto de una carga indebida (undue burden), entendida como el propósito o el efecto de interponer un obstáculo substancial en la vía de la mujer para obtener un aborto. Lo esencial es la preservación del derecho de la mujer a adoptar la última decisión sobre la práctica del aborto antes de la viabilidad del feto. ${ }^{63}$

Aplicando este test a las restricciones establecidas por el Estado de Pennsylvania, la opinión de la Juez $\mathrm{O}^{\prime}$ Connor estimó que las exigencias de consentimiento informado y plazo de espera eran constitucionalemente válidas. Esta decisión, que implicó la revocación de precedentes surgidos bajo Roe $v$. Wade, ${ }^{64}$ fue posible gracias a la concurrencia de los votos de los Jueces contrarios a la preservación del holding de Roe $v$. Wade. ${ }^{65}$ Aplicando el mismo test, la opinión de la Juez O'Connor concluyó que la exigencia de notificación al cónyuge era inconstitucional. A la luz de la evidencia presentada sobre la práctica social extendida de abuso marital, la opinión estimó que esa exigencia constituía en esos casos un obstáculo substancial para la decisión de la mujer. ${ }^{66}$ Esta decisión, que es consecuencia de la mantención del holding de Roe $v$. Wade, fue posible gracias a la concurrencia de los votos de los dos Jueces que eran partidarios de mantener además la regla de los trimestres. ${ }^{67}$ Si además se tiene presente que se trata de una decisión por apenas un voto de diferencia, resulta en verdad difícil imaginar una posición más precaria para una tesis jurisprudencial.

Pese a esa preciariedad, en los casi diez años que van transcurridos desde Casey, el nuevo estándar constitucional establecido por la opinión de la Juez O'Connor no ha sido seriamente cuestionado ante la CS. La razón de ello se encuentra en el mejor apoyo que esta tesis jurisprudencial pasó a tener en virtud de las designaciones de la

62 ldem, en las páginas 872-875.

$63 \mathrm{Idem}$, en las páginas 876-878.

64 City of Akron v. Akron Center for Reproductive Heaith, Inc., 462 L.S. 416, 452-474 (I983), Thornburgh v. American College of Obsretricians and Gynecologists, 476 U.S. 747, 814-833 (1986).

65 Cit., supra, nota 66 en las págs. 944-971.

66 Idem, en ias págs. 887-898. Esto implica naturalmente conceder al interés de autonomía reproductiva de la mujer, antes del nacimiento del feto, un peso substancialmente mayor que el interés de su cónyuge en la parernidad (idem, en las págs. 896-898).

67 Idem, en las págs. $911-944$. 
Juez Ginsburg y el Juez Breyer por el ex Presidente Clinton. ${ }^{68}$ Esto explica que durante la década de los noventa sólo se plantearan cuestiones laterales a la polémica sobre el derecho constitucional al aborto. ${ }^{69}$

La mayor dificultad experimentada por la CS bajo Casey provino de la regulación dirigida a prohibir un procedimiento abortivo, denominado "dilatation and extraction" (en adelante, "D\&X"). Esta es una variante del procedimiento usado con mayor frecuencia en los Estados Unidos para practicar el aborto en el segundo trimestre, denominado "dilatation and evacuation" (en adelante, "D\&E"). En uno y otro caso, parte del cuerpo del feto es desplazada a través del cervix antes de dársele muerte. La diferencia entre uno y otro método es que en D\&E la parte del cuerpo desplazada es un miembro, y ese desplazamiento tiene por objetivo el desmembramiento, mientras que en $\mathrm{D} \& \mathrm{X}$ se desplaza íntegramente la parte superior o inferior del cuerpo, para poder intervenir en el cráneo del feto con el fin de darle muerte.

En la década de los noventa, más de treinta Estados establecieron leyes prohibiendo el procedimiento D\&X, denominándolo por lo general como "aborto con nacimiento parcial". El fundamento de esta prohibición radicaba en su consideración como un procedimiento abortivo innecesario y prácticamente indistinguible del infanticidio. Estas prohibiciones fueron deciaradas inconstitucionales en la mayoría de los casos en que se promovió una controversia ante tribunales federales. ${ }^{70}$ En el caso conocido por la CS, Stenberg v. Carhart $^{71}$ se trataba de la regulación establecida por el Estado de Nebraska, cuya inconstitucionalidad había sido declarada por el tribunal de distrito y el respectivo tribunal de circuito de apelaciones. ${ }^{72}$

La opinión de mayoría de la CS, redactada por el Juez Breyer ${ }^{73}$, confirmó la inconstitucionalidad de la regulación, basándose en dos argumentos. Por una parte,

68 Con estas designaciones, que sustituyen a los Jueces White y Blackmun, la mantención del holding de Roe $v$. Wade, operada en la opinión de $\mathrm{l}_{2}$ Juez O'Connor ha pasado a ser respaldada por seis votos contra tres.

69 Estas son: (1) controversias telacionadas con limitaciones legales o protecciones contra manifestantes ante establecimiento donde se practican abortos: Bray v. Alexandria's Wornen Health Clinic, 506 U.S. 262 (1993), Hill v. Colorado, 530 L'S. 703 (2000); (2) cuestiones relacionadas con el criterio para justiffcar una "inconstitucionalidad facial" de una disposición, es decir, sin atender a sus posibles alternativas interpretativas: Ada v. Guam Society of Obsterricians \& Gynecologists, 506 U.S. 1011 (1992), Fargo Women's Health Organization v. Schafer, 507 L.S. 1013 (1993), Janklow v. Planned Parenthood, Sioux Falls Clinic, 517 U.S. 1174 (1996); y (3) controversias sobre puntos resueltos por la jurisprudencia anterior: Mazureck v. Armstrong, 520 U.S. 968 (1997), Voinovich v. Wornen's Medical Professional Corporation, 523 U.S. 1036 (1998).

70 Al respecto, vid. The Supreme Court, 1999 Term Leading Cases, I. Constitutional Law, en: Harvard Law Review, Voi. 114 (2000), págs. 219-227.

71530 U.S. 914 (2000).

72 Cathart v. Stenberg, 11 F. Supp. 2d 1099 (D. Neb. 1998), confirmada en 192 F. 3d 1142 (80 Cir. 1999).

73 La opinión fue apoyada por las Jueces $\mathrm{O}^{\prime}$ Connor y Ginsburg (ambas con opiniones concurrentes separadas) y los Jueces Stevens y Souter (el primero con opinión concurrente). El Juez Kennedy, que como se recordará apoyó Cascy en su momento, emitió una opinión disidente, sosteniendo que la prohibición del D\&X del Estado de Nebraska no imponfa una carga indebida (undue burden) para el ejercicio del derecho a abortar de la mujer.

74 La sección 28.326 (9) de la ley respectiva definia el concepto de "partial birth adoption" como "an abortion procedure in which the person performing the abortion partially delivers vaginally a living unborn child before killing the unborn child and completing the delivery" (cit., supra, nota 81, en la pág. 922). 
la CS estimó que la redacción de la disposición respectiva ${ }^{74}$ no permitía distinguir entre el procedimiento D\&X y el procedimiento D\&E, y que la consecuencia de prohibir este último, dada su ordinaria ocurrencia, implicaba la imposición de una carga indebida (undue burden) para el ejercicio del derecho a abortar reconocido en Casey. ${ }^{75}$ Por otra parte, la CS consideró inconstitucional que la prohibición del D\&X no reconociera una excepción para el caso de la puesta en peligro de la salud de la madre. ${ }^{76}$ Este segundo argumento es particularmente importante, por dos razones. Primero, porque clarifica la relevancia autónoma de la protección de la salud de la mujer como excepción constitucionalmente protegida respecto de cualquier prohibición del aborto, para cualquier estadio del embarazo. Esta clarificación tiene lugar mediante un argumento a fortiori: si la prohibición del aborto después de alcanzada la viabilidad del feto debe reconocer una excepción en la puesta en peligro de la salud de la madre, con mayor razón debe reconocerse esa excepción antes de ese estadio." En segundo término, el argumento es importante porque precisa que la protección de la salud de la mujer como justificación del aborto tiene lugar no sólo respecto de los peligros que son inherentes al embarazo, sino de los riesgos emanados del procedimiento abortivo utilizado. El derecho a usar un procedimiento abortivo que elimine riesgos relevantes conforme al juicio razonable y fundado del médico, en este caso el D\&X, está cubierto por la excepción protectiva de la salud de la mujer. ${ }^{78}$

Finalmente, Carhart se encarga de precisar cuál es el holding de Casey, describiéndolo como la conjunción de tres principios: (1) antes de la viabilidad, la mujer tiene derecho a escoger el término de su embarazo, (2) una norma legal establecida para implementar el interés del Estado en la protección de la vida fetal que imponga una carga indebida (undue burden) en la decisión de la mujer antes de la viabilidad es inconstitucional, (3) después de la viabilidad, el Estado puede legítimamente, si así lo escoge para proteger la vida fetal, regular o incluso prohibir el aborto, excepto cuando el aborto es necesario, conforme a un adecuado juicio médico, para la preservación de la salud o la vida de la madre. ${ }^{79}$ Este es el derecho constitucional vigente en los Estados Unidos de Norteamérica.

75 Idem., en las págs. 938-946.

76 Idem, en las págs. 929-938.

77 Idem, en la pág. 930.

78 ldem, en las págs. 931-933. Como acertadamente lo expone el Juez Kennedy en su disidencia, ía cuestión central de la configuración de esta excepción, dejada sin resolver por Carhart, es el grado que elia autoriza de control judicial de la concurrencia de sus presupuestos objetivos. En términos de derecho comparado la pregunta es: ¿ ¿s ésta una excepción concebida como el modelo europeo de las indicaciones, que autoriza el control judicial ex post de la corrección del diagnóstico médico, o por el contrario sigue la fórmula de la intervención médica no sujeta a control configurada por Roe $v$. Wade y Doe $v$. Bolton para el modelo del plazo? Notablemente, esta es la misma pregunta que se encuentra en los orfgenes de la jurisprudencia de la CS sobre el aborto, United States $v$. Vuitch, 402 U.S. 62 (1971).

79 Idem, en la pág. 921. 


\section{La Constitución como límite a la despenalización del aborto consentido: la jurisprudencia del Tribunal Constitucional Federal alemán $^{80}$}

\subsection{La posición originaria.}

El TS se ha pronunciado solamente dos veces acerca de las relaciones ente la Constitución y la regulación legal del aborto consentido. La posición originaria se encuentra en su primera sentencia sobre la interrupción del embarazo ${ }^{81}$. Esta sentencia recayó en un procedimiento de control abstracto de normas de carácter preventivo, en el cual el TS se pronunció acerca de la constitucionalidad de la 5a. Ley de Reforma del Derecho Penal, aprobada por el Bundestag, que modificaba la regulación preexistente del aborto en el Código Penal estableciendo un sistema de plazo con consejo forzoso. ${ }^{82}$ El TS decidió que semejante regulación era incompatible con la Ley Fundamental (en adelante, "LF") alemana.

El punto de partida del razonamiento del TC es que la norma que consagra el derecho

80 En general, sobre el debate acerca del aborto en el derecho alemán: Claus Roxin, La propuesta minoritaria del Proyecto Alternativo (1971), en: del mismo, Problemas Básicos del Derecho Penal, Madrid, 1976, págs. 71-83; Reinhart Maurach, Friedrich-Christian Schroeder, Manfred Maiwald, Strafrecht - Besonderer Teil, 1, 8a ed., 1995, págs. 66-92; Erhard Kausch, Legalität und Moralität im jüngsten Abtreinungsurteil des Bundesverfassungggerichts, en: Archiv für Rechts- und Sozialphilosophie Vol. 81 (1995), págs. 496-516; Hans-Joachim Rudolphi, Comentarios a los $\$ 9$ 218-219 del Código Penal alemán, en: del mismo et al., Systematischer Kommentar zum Strafgestezbuch, II, 5a ed., 38a entrega, 1996; Albin Eser, Comentario a los \$f 218-219 del Código Penal alemán, en: SchörkeSchröder, Strafgesetzbuch - Kommentar, 25a ed., 1997; el mismo: Reforma de la regulación del aborto en el derecho penal alemán: Evolución y primeras experiencias, en: del mismo, Derecho Penal, Medicina y Genética, Lima, 1999 , págs. 135-166; Isabel Zoder, Reforma y regulación legal del aborto a la luz de la jurisprudencia del Tribunal Constitucional alemán, en: Anuario de Derecho Penal y Ciencias Penales (Madrid), Vol. 49 (1996), págs. 219-280; Martin Koppernock, Das Grundrecht auf bioethische Selbstbestimmung, Baden-Baden, 1997. Para un conjunto plural de apreciaciones de la sentencia del TS de 1993, vid. el número especial $1 / 1993$ de Kritische Vierteljahresschrift für Gesetzgebung und Rechtswissenschafi (KritV), Baden-Baden, págs. 116-198.

81 BVerfGe 39. I (1975), sentencia de 25 de febrero de 1975. La sentencia contiene votos disidentes de la Juez Rupp-v. Brünneck y del Juez Simon.

82 El Código Penal alemán es legislación federal, vinculante para todos los Länder. Conforme al derecho vigente a la época, el aborto se encontraba sancionado penalmente; la impunidad sólo podía afirmarse con carácter excepcional mediante una causa de justificación o de exculpación; para el caso del aborto terapéutico se contaba con una causa de justificación creada jurisprudencialmente, el estado de necesidad supralegal (RGSt 6I, 242 [1 1.03.1927], BGHSt 2, I I [ [15.01.1952]). En 1972 se presentó al Bundestag un proyecto gubernativo que establecía un régimen más amplio y tnejor diferenciado de causas de justificación para el aborto consentido y practicado por un médico (modelo de las indicaciones). Lo que el Bundestag aprobó en 1974 como 5a. Ley de Reforma del Derecho Penal fue el proyecto presentado por parlamentarios de los partidos socialdemocráta $y$ liberal (SPD/FDP). Esta regulación eximía de pena por el delito de aborto cuanda era practicado con el consentimiento de la mujer, por un médico, antes de que trascurrieran doce semanas desde la concepción $(\$ 218 \mathrm{a}$ ), estableća una indicación terapéutica y una indicación embriopácica para el aborto consentido que se practicaba por un médico con posterioridad al transcurso del plazo antedicho $(\$ 218 \mathrm{~b})$, y establecía sanciones especiales para el aborto consentido practicado dentro del plazo pero sin cumplir con el procedimiento de consejo previo (\$ 218c), como asimismo para el aborto consentido practicado una vez vencido el plazo sin el procedimiento de constatación de la concurrencia de los presupuestos de las indicaciones ( $\$ 219)$. La mujer embarazada estaba excluida de estas dos sanciones adicionales. 
a la vida (Art. 2-II, primera oración de la LF) protege la vida del nasciturus que se desarrolla en el vientre materno como bien jurídico independiente. ${ }^{8.3}$

El ámbito de protección del derecho a la vida es determinado por el TS en función de la existencia del ser humano, cuyo inicio se encuentra fuera de duda desde un punto de vista biológico-frsiológico a partir del día decimocuarto desde la concepción. Desde este momento se produce un proceso continuo de desarrollo que no admite una diferenciación precisa entre las distintas etapas. Conforme a este punto de vista, ni el parto ni la viabilidad son criterios que puedan justificar la reducción del ámbito de protección del derecho a la vida: protegido por este derecho está todo aquel que vive. Esta interpretación extensiva se encuentra por lo demás respaidada por el fin de protección de la norma constitucional: una interpretación restrictiva haria incompleto el aseguramiento de la vida humana frente a intervenciones del Estado. ${ }^{87}$

Esta premisa no implica la consideración del nasciturus como titular de un derecho subjetivo público. El TS no llega a afirmarlo, porque no necesita pronunciarse al respecto. En el contexto del caso, es suficiente la consideración de la vida del nasciturus como bien jurídico protegido de rango constitucional, y para ello basta con la consideración de la norma sobre el derecho a la vida como norma objetiva, es decir, como parte del orden valorativo objetivo establecido por la Constitución. ${ }^{85}$

Lo que sí implica la premisa para el T'S, es un deber constitucional de protección de la vida del nasciturus cuyo destinatario es el Estado. Esta consecuencia es además respaldada por el deber de proteger la dignidad humana, explícitamente establecido por la LF (Art. 1-I, segunda oración), ya que la dignidad está presente en toda vida humana. "Este deber de protección es exhaustivo, y no se agota en la prohibición de afectar la vida del nasciturus, sino que exige del Estado que intervenga protegiéndolo y favoreciéndolo, ante todo frente a ataques provenientes de terceros. Mientras mayor sea el rango jerárquico del bien jurídico cuya protección es debida, más seriamente ha de tomarse este deber de protección. Y la vida humana es un valor máximo del orden constitucional, ya que constituye la base vital de la dignidad humana y el presupuesto de todos los demás derechos fundamentales. ${ }^{{ }^{\urcorner}}$

8.3 BVerfGE 39, 36.

84 Cit., pág. 37-38. Esta interpretación extensiva es apoyada además por $\mathrm{cl}$ TS con argumentos provenientes de la historia fidedigna del establecimiento de la norma conscitucioná, y ei reconocimiento del carácter de bien juridi. co merecedor de protección de la vida del nascaturus que se efectuo en el marco de la discusiór pariamentaria ce ia 5a. Ley de Reforma del Derecho Penal (págs. 39-40).

$85 \mathrm{ldem}$, págs. $41-42$. La concepción de las normas relativas a los derechos fundamentales como un orden valorativo objetivo, que en su calidad de decisión fundamental juridico-constitucional vale para todos los ámbitos del ierecho $y$ da impliso y directices a ia legisiación, administraciór y yusprucencia es una de las iesis caracieristicas de ia jurisprudencia constitucional alemana. Al respecto, vid. BVerliE 7,198 , en ia pág. 205 y 35, 79 , er. la pág. 114. Sobre esta concepción, y su reformulación como teoria de los principios constitucionales, Robert Alexy, Tearia de los Derechos Fundamentales, Madrid, 1993, págs. 138-171 y 503-554.

86 I $\mathrm{dem}$, pag. $4 \mathrm{i}$

8: Idem. pág. 42. 
$\mathrm{Al}$ mismo tiempo, el TS reconoce que el embarazo pertenece al ámbito de protección de un derecho de la mujer a la autonomía en su esfera íntima, basado en el derecho general a la libertad de acción (Art. 2-I LF, en conjunción con el principio de la intangibilidad de la dignidad humana) ${ }^{88}$ Niega sin embargo que este derecho haga ilegítimo para el Estado intervenir en favor de la vida del nasciturus. De la condición independiente del nasciturus como un ser humano deduce el TS su estatus de accesible y necesitado de una regulación estatal. El derecho de autonomía de la mujer puede legitimar su posterior decisión contraria a asumir las responsabilidades de la maternidad, pero no es suficiente para legitimar la destrucción de la vida de otro. La naturaleza de las cosas es lo que hace que la vida del nasciturus constituya un límite para la autonomía de la mujer. ${ }^{89}$

EI TS niega que sea posible una compatibilización entre ambos intereses en conflicto, que pueda garantizar la protección de la vida del nasciturus y la libertad de la mujer para interrumpir el embarazo, pues el reconocimiento de esta última significa la eliminación de la vida del nasciturus. Realizada la ponderación desde el punto de vista de la intangibilidad de la dignidad humana, a juicio del TS debe reconocerse el rango preponderante de la vida del nasciturus. Ello, porque la intensidad de la afectación de la vida del nasciturus que se seguiría de permitir el aborto es incomparablemente mayor que la intensidad de la afectación de la autodeterminación de la mujer que se sigue de prohibir el aborto. Esta ponderación debe, pues, resolverse en una preferencia por la vida del nasciturus. ${ }^{90}$

De lo anterior el TS deduce un deber para el ordenamiento jurídico de expresar el deber de la mujer de sobrellevar el embarazo, y por lo tanto de declarar antijurídico al aborto, aun el consentido. En particular debe evitarse la falsa impresión de que la práctica de un aborto sea equivalente a cualquier otra intervención médica efectuada para sanar una enfermedad o una aiternativa jurídicamente irrelevante al uso de medios anticonceptivos."

Con todo, el TS reconoce que en casos excepcionales la ponderación de intereses deba o pueda decidirse en favor de la mujer embarazada. El fundamento de esta consideración se encuentra en la inexigibilidad de la carga que excede la medida de afectación de la alitonomía de la mujer que normalmente va unida al embarazo. En casos en que por su especial configuración se agrave extraordinariamente para la mujer el cumplimiento de su deber de sobrellevar el embarazo, originándose un serio conflicto interno para ella, el respeto a la esfera de la personalidad de la mujer exige del Estado una actitud de consideración hacia su decisión autónoma. ${ }^{92}$ Claramente inexigible es el deber de sobrellevar el embarazo en los casos en que ello constituya un peligro para la

88 Idem, pág. 43.

89 Loc. cit.

90 Idem. págs. 43-44.

91 Idem, pág. 44.

92 Idem, pág. 48. 
vida o un grave peligro para la salud de la mujer. La LF permite también al legislador configurar otros supuestos en los que la carga extraordinaria impuesta a la mujer sea de una gravedad equivalente desde el punto de vista de la inexigibilidad, como en las indicaciones embriopática ("eugenésica"), ética (criminológica) o social (situación general de necesidad). En todos estos casos, el punto de vista decisivo es que desde la perspectiva de la Constitución un interés digno de protección se hace valer con tal urgencia, que el ordenamiento jurídico estatal no puede exigir de la mujer el reconocimiento del rango preponderante de la vida del nasciturus. ${ }^{23}$ Fuera de estos casos, la interrupción del embarazo debe ser calificada por el derecho como un acto antijurídico. ${ }^{94}$

Este resultado no implica sin más que el Estado tenga un deber de punición del aborto fuera de los casos de inexigibilidad. La LF sólo impone un deber de protección efectiva. La decisión acerca del modo como se satisface ese deber corresponde primariamente al legislador. La cuestión acerca de en qué medida el Estado se encuentra obligado por la Constitución a usar el derecho penal como medio de protección de la vida del nasciturus requiere una examinación global, que por una parte incluya la consideración del valor del bien jurídico lesionado y la medida de dañosidad social de la acción lesiva, también en comparación con otras acciones penalmente sancionadas, y que por otra parte no pierda de vista la regulación tradicional de la materia, la evolución de las concepciones acerca de rol del derecho penal en la sociedad moderna, la efectividad práctica de la conminación penal y la posibilidad de su substitución con otras sanciones. ${ }^{95}$

En relación con la punición del aborto, el TS considera que el legislador no está obligado a adoptar las mismas medidas que las que adopta frente al homicidio. No obstante ello, dada la condición de acción letal del aborto, se encuentra fuera de duda la necesidad de que el legislador exprese con claridad su carácter antijurídico. Su punición es también indudablemente legítima, pero no puede afirmarse para el Estado un deber absoluto de sancionarlo penalmente. La intervención del derecho penal depende esencialmente de una decisión del legislador, y éste no se encuentra en principio impedido de expresar de otra forma la antijuridicidad del aborto. Lo esencial es que se garantice una protección efectiva del bien jurídico. Por esta razón, en el caso extremo en que la protección ordenada por la Constitucion no pueda alcanzarse con otra medida, puede entenderse que el legislador está obligado a hacer uso del derecho penal. Esto no quita el carácter de ultima ratio de la sanción penal. El deber de ejercer el ius puniendi es una "obligación relativa" del Estado, que surge de la insuficiencia de todos los demás medios de protección. ${ }^{96}$ Esta obligación relativa está sujeta además a un examen de ponderación de los intereses en conflicto (bien jurídico protegido vs. dere-

93 Idem, págs. 48-50.

94 Idem, pág. 51.

95 Idem, pags. 44-45

96 Idem, págs. 45-48. 
cho fundamental afectado por la sanción) conforme al orden valorativo de la LF y al principio constitucional de la proporcionalidad. Con todo, es una obligación susceptible de ser derivada del deber de protección establecido por la Constitución. ${ }^{97}$

Aplicando estos estándares a la regulación sometida a control constitucional, el TS concluye que sus disposiciones no cumplen cabalmente el deber de expresar con claridad la antijuridicidad del aborto cometido fuera de los casos de inexigibilidad, se fundamentan en una justificación inaceptable de la muerte de algunos embriones o fetos como medio para proteger a otros, y no establecen un procedimiento de consejo forzoso que pueda ser considerado como medida satisfactoria de protección efectiva sustitutiva de la sanción penal. Por tales razones, el TS declaró inconstitucional la ley y la invalidó. ${ }^{98}$

\subsection{La evolución posterior.}

Basándose en la sentencia del TS, el Bundestag aprobó en 1976 la 15a Ley de Modificación del Derecho Penal, que estableció un sistema amplio de indicaciones. El aborto consentido por la mujer y practicado por un médico quedaba justificado, si resultaba adecuado para evitar un peligro para la vida o un peligro de grave afectación del estado de salud corporal o mental de la mujer, conforme a un juicio médico y tomando en consideración las relaciones vitales presentes y futuras de la mujer $(\$ 218 \mathrm{a}-\mathrm{-})$. Por expresa disposición legal, se consideraban incluidos dentro de esta "indicación médico-social" los casos de las indicaciones embriopática (grave malformación del feto), ética o criminológica (origen del embarazo en un abuso sexual) y social (situación de grave necesidad de la mujer) ( $\$ 218 \mathrm{a}-\mathrm{II}$ y III). Las indicaciones social y crimonológica solo justificaban el aborto practicado dentro de las doce primeras semanas del embarazo. La indicación embriopática justificaba el aborto hasta el término de la vigesimosegunda semana de embarazo. La práctica del aborto en estos supuestos se sujetaba a un procedimiento de consejo forzoso ( $\$ 218 \mathrm{~b}$ ) y a una exigencia de certificación de un segundo médico $(\$ 219 \mathrm{a})$. Finalmente, para la mujer que cumplía con el procedimiento de consejo forzoso y se hacía practicar un aborto por un médico, la ley preveía una causa personal de exclusión de la punibilidad (\$218-III).

En los hechos, esta regulación tuvo el carácter de un sistema de plazo encubierto. Más del ochenta por ciento de la alta tasa de abortos lícitos en Alemania tenían lugar bajo la indicación social, sin que existiera un control efectivo de la concurrencia de sus presupuestos objetivos por parte del Ministerio Público ni de las entidades de salud previsional. Los casos de aborto ilegal detectados por el sistema eran excepcionalísimos, mientras que el turismo abortivo florecía, principalmente hacia Holanda.

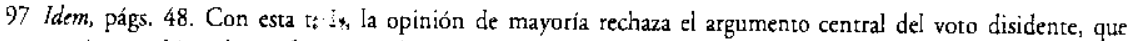
consiste en objetar la tranformación de un sistema de prohibición al Estado de afectar libertades en un sistema de mandatos de privar de libertad.

98 ldem, págs. 53-68. 
Si bien el descontento con la regulación vigente en la República Federal Alemana era extendido, el factor desencadenante de su reforma no provino de un impulso de la política interna de la antigua República Federal Alemana, sino del proceso político desencadenado por su unificación con la antigua República Democrática Alemana, donde el derecho vigente establecía un sistema de plazo, ideológicamente fundamentado en el derecho a la igualdad de las mujeres en el Estado Socialista. ${ }^{n i}$ La solución a esta importante discrepancia no se logró con ocasión de la reunificación, sino que por un tiempo siguieron vigentes en sus ámbitos originales ambas regulaciones. En el Tratado de Lnificación de 31 de agosto de 1990 se estableció al respecto lo siguiente:

\section{"Artículo 31 \\ Familia y Mujeres}

(4) Es tarca del legislador alcmán común adoptar a más tardar hasta el 31 de diciembre de ¿ 992 una reguiación que garantice la protección de la vida prenatal y la superación conforme a la Constitución de situaciones de conflicto de mujeres embarazadas, especiaimente mediante derechos jurídicamentc asegurados a asesoria y ayuda social, de mejor modo que como es actualmente d caso en ambas partes de Alemania ": "."

Esta es una norma sagazmente formulada. Por una parte, la norma pone de manifiesto que el respeto del límite constitucional de la LF de la República Federal es una condición ineludible para la unificación. Esto implica asumir como dato que se encuentra fuera de discusión la relevancia constitucional de la vida del nasciturus en tanto límite de cualquier política legislativa sobre el aborto. Por otra parte, la norma se abre a la consideración de la regulación del Código Penal alemán, basada en una decisión del IS, como una regulación defectuosa y susceptible de modificaciones. Finalmente, la norma pone el énfasis de la solución del conflicto a través de prestaciones sociales del Estado, aspecto que constituía el denominador común entre ambos sistemas.

En cumplimiento del cometido impuesto por el Tratado, el Bundestag aprobó la Ley de Asistencia a la Familia y la Mujer Embarazada, de 27 de julio de 1992, que en lo esencial estableció un sistema de plazo con consejo forzoso como causa de justificación del aborto consentido. En la regulación del procedimiento de consejo se establece como orientación fundamental la protección de la vida del nasciturus, aunque bajo la exigencia dc reconocer y promover la decisión autónoma de la mujer. El plazo se limita a las doce primeras semanas de embarazo, y en lo demás se mantiene el reconocimiento de la indicación embriopática, limitada al término de la vigesimosegunda

99) \$9:53-155(… de la RI)A (versión de 14.12.1988), Ley sobre la lntcrupción del Embarazo de 9 de marzo de

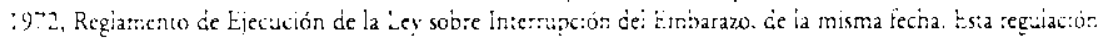
reconocia a a mujer el derccino al aborto dentro de as pumeras coce semanas de embarazo con poster:or:iac se lo permitía en caso de peitgro para la vida de ia mujer o cuando concurrieran otras graves circiarsancias. ia reguiación establecfa el deber de practicar ei aborto er: icas y hospitales esratales como tratamenio ambulatorio, como asimistro un deber de conseio a la mujer, ïnuado a la jrformación sonre la intervención redica y a us meiodos anciconceprivos que evitarían ur, ruevo aborio.

100 Ciado según Rudolphi, op. cit., supra, nota 80, pág. 15 (iraćucción personal). 
semana del embarazo, y de la indicación médica sin limitaciones, así como de la causa personal de exención de punibilidad de la mujer.

La constitucionalidad de esta nueva regulación fue impugnada por el Gobierno del Estado Libre de Baviera y 249 parlamentarios del Bundestag. Esta impugnación originó el segundo pronunciamiento del TS sobre las limitaciones constitucionales a la legislación sobre el aborto consentido.

\subsection{La posición actual.}

En su segunda decisión sobre la interrupción del embarazo ${ }^{101}$ el TS volvió a declarar inconstitucional y a invalidar la legislación aprobada por el Bundestag. Sin embargo, haciendo uso de su potestad de dictar una reglamentación de ejecución, el TS estableció tambien un sistema de plazo con consejo forzoso. Las diferencias entre la reglamentación del TS y la ley del Bundestag se centran en la consideración del aborto practicado dentro del plazo y conforme al procedimiento de consejo forzoso, pero fuera de los casos de inexigibilidad, como una acción justificada (Bundestag) o como una acción antijurídica pero no sancionada penalmente (TS).

El punto de partida del TS se encuentra en la reiteración de su premisa anterior. La LF establece un deber para el Estado de proteger la vida humana, que abarca indiscutidamente la vida del embrión anidado al útero de la mujer. La dignidad humana se manifiesta alli donde hay vida, en el propio interés de ese ser individual, obligando al ordenamiento jurídico a garantizar su desarollo en el sentido de un derecho a la vida propio del no nacido, cuyo reconocimiento no depende de su aceptación por la madre. ${ }^{102}$

El Estado debe responder a este deber de protección mediante el establecimiento de mandatos y prohibiciones, incluyendo una prohibición de atentar en su contra dirigida a la mujer embarazada. Dada la peculiar situación en que se encuentran la mujer y el embrión o feto (relación de "duplicidad en la unidad"), la protección de éste exige del Estado el establecimiento para aquella de un deber fundamental de sobrellevar el embarazo. La prohibición del aborto y el deber de sobrellevar el embarazo son dos elementos indisolubles de la protección constitucionalmente ordenada. Estos deberes deben tener el carácter de auténticos imperativos jurídicos, propios de un ordenamiento que aspira a la vigencia efectiva, vinculantes y provistos de consecuencias jurídicas. El deber de protección de la vida no es sin embargo un deber absoluto, en el sentido que no reconozca límites frente a otros bienes jurídicos. Particularmente afec-

101 BverfGE 88, 203, sentencia de 28 de Mayo de 1993. La sentencia contiene los votos disidentes de los jueces Mahrenholz y Sommer, y del voto (parciaimente) disidente del Juez Böckenförde. Este último comparte e] razonamiento fundamental de la mayorfa, discrepando en relación con algunas consecuencias. Los otros dos jueces sostienen la constitucionalidad del sistema de plazo con consejo forzoso como causa de justificación del aborto consentido, fundado en la preponderancia del derecho a la auronomía de la mujer.

102 Idem, págs. $251-252$. 
tados por la protección de la vida del nasciturus resultan la dignidad, el derecho a la vida y la intangibilidad corporal y el derecho a la personalidad de la mujer embarazada. ${ }^{103}$

La determinación en detalle del modo y el alcance de la protección es tarea del legislador. La Constitución impone la protección como fin pero no los aspectos precisos de su implementación. Con todo, el legislador debe satisfacer la prohibición de defecto (Untermaßverbot), que exige una protección adecuada, en el sentido básico de ser un medio efectivo para el fin perseguido. ${ }^{104}$ De esta prohibición de defecto se deducen exigencias mínimas que deben ser satisfechas por el ordenamiento jurídico. En primer lugar, el aborto debe encontrarse jurídicamente prohibido. El conflicto de intereses entre la protección de la vida del nasciturus y los derechos de la mujer no puede ser resuelto válidamente por el legislador mediante la prescindencia de esa prohibición como regla general, ni aun para la fase temprana del embarazo. ${ }^{\text {i0 }}$ Esto no significa los casos excepcionales no autoricen, con base misma en la Constitución, a eliminar el deber de sobrellevar el embarazo. El criterio de reconocimiento de estos casos excepcionales es la inexigibilidad. Las indicaciones médica, criminológica y embriopática son casos de exención de ese deber con base en la Constitución. Los demás casos deben orientarse a la identificación de una situación de necesidad cuya gravedad sea equivalente. $^{106}$

En principio, tratándose de un deber elemental de protección del Estado, como lo es en relación con la vida humana respecto de los atentados en su contra, la prohibición de defecto no permite prescindir del uso del derecho penal. Ciertamente no es éste el medio primario de dispensar protección jurídica; pero aun como ultima ratio debe ser empleado cuando un comportamiento además de prohibido requiere urgentemente ser impedido, porque reviste una particular dañosidad social y resulta intolerable para la convivencia humana. En todo caso, bajo la Constitución no basta para satisfacer este deber de protección con que el Estado defienda el bien frente a ataques de terceros. El deber de protección exige del Estado que intervenga, contrapesando los factores que originan esos ataques. Para cumplir con su deber de protección, el Estado debe adoptar medidas satisfactorias de carácter normativo y fáctico, que en conjunto otorguen una protección adecuada y efectiva. Esto exige desarrollar un concepto de protección que combine elementos preventivos y represivos. La elaboración e implementación normativa de semejante concepto de protección es cuestión del legislador. Éste no se encuentra libre para permitir el aborto más aillá de los casos excepcionales de inexigibilidad, pero sí puede determinar en qué forma hace efectiva, en los distintos ámbitos del ordenamiento jurídico, la prohibición del aborto. ${ }^{107}$ 
De lo anterior se desprende que al legislador no le está fundamentalmente prohibido pasar a un concepto de protección que ponga el énfasis en el consejo de la mujer embarazada para la protección del nasciturus en la fase temprana del embarazo, con el fin de ganar su voluntad, y con tal motivo prescindir de la sanción penal y la configuración de indicaciones. A juicio del TS, el Bundestag realizó ese cambio en el concepto de protección basado en consideraciones defendibles. El cumplimiento del mandato impuesto por el Art. 31-IV del Tratado de Unificación, junto a la insatisfacción generalizada con el sistema de indicaciones de la República Federal Alemana, esto último debidamente acreditado, hacen a su juicio justificable la convicción acerca de la inidoneidad de la sanción penal como medio de protección de la vida del nasciturus, y la necesidad de sustituirlo. ${ }^{108}$

Un sistema de protección preventivo como el escogido por el Bundestag tiene por objetivo dirigirse a la mujer que considera la práctica de un aborto con el fin de reforzar su responsabilidad personal, para ganar su voluntad. Esto requiere ciertas condiciones institucionales que provean los presupuestos positivos para una decisión de la mujer en favor de la vida del nasciturus. Sólo de esa forma puede justificarse la prescindencia de indicaciones como medio de protección efectivo para la vida del nasciturus. El procedimiento de consejo debe orientarse a esclarecer ante la mujer el deber jurídico de sobrellevar el embarazo y a alentar su aceptación o cumplimiento. Esto requiere que el médico y el personal de asesoría participen de esta orientación. Asimismo, se debe prescindir de la configuracion legal de una indicación general basada en una situación de necesidad: si el procedimiento de consejo quiere ser efectivo, no puede colocar a la mujer en una situación de tener que acreditar ciertas circunstancias para justificar su decisión en favor del aborto. El principio de la inexigibilidad debe valer en todo caso como criterio orientador de la decisión de la mujer en el contexto del procedimiento de consejo. Por otra parte, la efectividad del consejo requiere que el aborto no sea declarado como permitido o justificado. La ley a lo más puede excluirlo del tipo penal, pero no puede asignarle una condición jurídica incongruente con la Constitución. Además, la ley no puede dejar a cargo de la mujer embarazada la comprobación de la concurrencia de una indicación. Finalmente, la juridicidad del aborto no es indispensable para la efectividad del procedimiento de consejo, si se adoptan medidas específicas en relación con algunas consecuencias de su antijuridicidad. ${ }^{109}$

El planteamiento anterior acerca de las condiciones mínimas de un sistema de consejo efectivo como medio de protección de la vida del nasciturus es el núcleo del razonamiento del TS para justificar la prescindencia de la pena como medio de protección. Las consecuencias que deduce de él constituyen el aspecto más discutido de su sentencia. Por una parte, el TS desarrolla a partir de este concepto de consejo efectivo reglas relativas a los procedimientos y demás requisitos, hasta en los detalles más espe- 
cíficos, del consejo a la mujer que anuncia su decisión de abortar y la atención médica a la mujer que persiste en esa decisión. ${ }^{110}$ Por otra parte, el TS concluye que el concepto de consejo efectivo, a la vez que impone al legislador mantener la prohibición del aborto consentido, exige evitar algunas consecuencias de esa condición antijurídica. Se trata de las consecuencias que pueden tener un efecto disuasivo para la mujer, obstaculizando de ese modo el éxito del procedimiento de consejo. Así, debe excluirse la admisibilidad de una legítima defensa del embrión o feto, el contrato de prestación de servicios médicos a la mujer debe ser válido y efectivo, debe garantizarse el secreto médico en relación con el aborto y las razones de la decisión de la mujer, e incluso debe proveerse a la mujer necesitada de medios la asistencia social mínima. ${ }^{111}$

Esto último equivale a prescindir de las consecuencias que se derivan del carácter antijurídico del aborto consentido en todos estos aspectos, pese a tratarse de un ataque prohibido por la ley y la Constitución. A juicio del TS, el deber de protección de la vida humana no nacida lo permite. El legislador está obligado a prohibir el aborto, pero no a hacer efectivas todas las consecuencias que de esa prohibición se deducen. Aquellas consecuencias que obstaculizarían el procedimiento de consejo como método efectivo de protección de la vida del nasciturus pueden y deben ser removidas en la configuración de dicho sistema. Es sólo en la medida de lo imprescindible para la efectividad del procedimiento de consejo que deben equipararse las consecuencias del aborto prohibido a las del aborto permitido por una indicación, cuando ha mediado dicho procedimiento. ${ }^{1.2}$

Aplicados estos estándares a la regulación aprobada por el Bundestag, era obvio que ella no podía satisfacerlos. Consecuentemente, el TS la invalidó y estableció en su lugar una reglamentación de ejecución de su decisión, que concretaba en detalle el concepto de protección mediante un sistema de consejo efectivo que a su juicio se derivaba de la Constitución. Finalmente, el legislador recogió esta regulación en la Ley de Solución de Conflictos de la Mujer Embarazada, de 21 de agosto de 1995, estableciendo el "modelo de plazo sin justificación y con deber de consejo". Este es el derecho penal vigente en Alemania. ${ }^{113}$ Sus presupuestos, expresados en la sentencia del TS, son el derecho constitucional alemán vigente.

110 ldem, págs. $28:-298$

111 ldem, pág. 279, en concordancia con las secciones D-V-6 y E-V-3-b). El subsidio estatal es considerado como obligatorio; no asi e! pago de los servicios médicos por las instiuciones de salud previsionai.

112 Idem, págs. 280-281.

i 13 El $\$ 218$ tipifica el aborto, calificando los casos de comisión contra la voluntad de la mujer o poniendo er peligro su vida o salud; la mujet tiene una penalidad disminuida y su tentativa no es punible. El \$218a-I establece la atipicidad del aborto solicitado por una mujer con posterioridad a'i procedimiento de consejo y practicado por un médico dentro de las doce primeras semanas de embarazo. Las disposiciones del $\$ 218 \mathrm{a}-\mathrm{II}$ y III establecen como causas de justificación las indicaciones médica (sin límite cronológico) y criminológica (dentro de las primeras doce semanas). La indicación embriopática no fue considerada como causa de justificación; esto es estimado como un grave error, ya que en la práctica se dan casos en que la detección de ía patologfa del feto se produce una vez transcurridas las primeras doce semanas de embarazo. EI \$218a-IV exime de pena a la mujer en caso de un aborto practicado por un médico después dé procedimiento de consejo y antes de que transcurran veintidós semanas desde la concepción; establece además una exención general facultativa, para el caso cn que la mujer se hubiera encontrado en un conflicto especial. 


\section{Comentarios}

\subsection{La diferencia fundamental.}

La primera observación que suscita la comparación de la jurisprudencia constitucional norteamericana con la alemana se relaciona con la magnitud y la persistencia de sus diferencias en la cuestión fundamental del estatus del nasciturus y del interés en su vida o sobrevivencia. La afirmación y la negación de un estatus del nasciturus equivalente al de los seres humanos nacidos son las tesis opuestas más firmes de una y otra jurisprudencia constitucional.

La afirmación de ese estatus ha desempeñado un rol importante en el debate políico norteamericano, incluyendo la política legislativa, pero nunca ha sido una tesis defendida como plausible en el contexto del debate entre los miembros de la CS. La disidencia frente a Roe $v$. Wade, Casey y Carhart se ha concentrado en la negación del estatus de derecho constitucional específico de la libertad de abortar de la mujer, y no en su afirmación para el interés en la vida potencial del embrión o feto. No es la imposición constitucional de un deber de prohibir el aborto consentido, sino la autorización constitucional al legislador para prohibirlo, si así lo quiere, lo que defiende la oposición a Roe $v$. Wade y a Casey. Por eso es que esa oposición se presenta como un reclamo democrático, que exige una restricción del intervencionismo de la CS en cuestiones de política legislativa, que va de la mano de un reclamo metodológico de contracción de su agenda interpretativa.

En el contexto del debate constitucional alemán, a la inversa, la negación de ese estatus nunca ha gozado de gran aceptación. ${ }^{114}$ La disidencia a las dos sentencias del TS se ha concentrado en la negación de un deber de punición del aborto como consecuencia del deber constitucional de proteger al nasciturus y en la consideración de la autonomía de la mujer como límite al cumplimiento por parte del Estado del deber constitucional de protección de la vida del nasciturus. No es la irrelevancia constitucional de la vida del nasciturus sino las consecuencias que de se relevancia se deducen para el Estado, en particular para la actividad del legislador, lo que se hace valer contra las decisiones del TS.

La evolución de la jurisprudencia del TS es una reacción a ese debate específico, y un reconocimiento de que la protección jurídica del nasciturus no exige protección penal, e incluso, que algunas consecuencias de la calificación del aborto como conducta antijurídica pueden ser disfuncionales para una mejor protección del nasciturus. Antes y después, la obligación del Estado, incluyendo al legislador, de proteger al nasciturus, constituye una premisa indiscutida.

114 La tesis tiene su destacado defensor en el contexto del debate de filosoffa moral y juridica en la persona de Norbert Hoerster (Abtreibung im säkularen Staat, 1991), pero ha permanecido como tesis aisiada en el contexto de la dogmática constitucional y penal. 
Por cierto, el rigor con que el TS formula y adopta esta premisa, no se encuentra exento de reparos. La fijación de la implantación como momento de reconocimiento de la existencia de una vida humana individual y el escrúpulo en reconocer al nasciturus titularidad de un derecho subjetivo público no son tesis congruentes con el asertivo planteamiento de que la mera existencia de un ser humano vivo es subsumible en el supuesto de hecho de la norma que reconoce derecho a la vida, ni con la negativa a aceptar el carácter progresivo del merecimiento de protección de ese ser. En particular, la aceptación de la legitimidad de diferencias sustanciales entre la regulación del aborto y la regulación del homicidio resulta incongruente con la equiparación sustancial de la vida del nasciturus y del nacido en el nivel del merecimiento constitucional de protección.

Algo semejante cabe señalar en relación con la tesis de la irrelevancia constitucional de la vida del nasciturus, sostenida por la CS. Que el hecho del nacimiento marque la adquisición del estatus de persona, y con ello de titular de derechos subjetivos públi$\cos$, es una tesis técnico-jurídicamente aceptable. Que de ello se deduzca la total irrelevancia constitucional de la vida humana previa al nacimiento, eso es algo harto más difícil de aceptar. Pues al fin y al cabo, esa vida es un presupuesto inmediato de la posterior adquisición de ese estatus. En los términos de su propio discurso, la evolución de la jurisprudencia de la CS no ha acarreado una modificación de su tesis en este aspecto. En los resultados, sin embargo, se ha producido de facto un reconocimiento al aumento de peso específico del interés en la protección de la vida del nasciturus.

Conforme al discurso explícito de la CS, la evolución que ha experimentado su jurisprudencia consiste en una redefinición del esquema institucional de garantías que flanquean el derecho al aborto, asegurando su ejercicio frente a la intrusión estatal dirigida a obstaculizarlo. La regla de los trimestres fue el esquema institucional de garantías predominante en la mayoría de los casos durante dieciséis ańos. El criterio de la carga indebida (undue burden) es el nuevo esquema que define el ámbito de protección del derecho. Frente a la actividad legislativa restrictiva del aborto, esta redefinición implica sin embargo en los hechos una revalorización del interés estatal en la protección de la vida del nasciturus. Por cierto, no hay una revalorización que implique un cambio de rango jerárquico, con efectos compulsivos para el Estado. Antes y después de Casey el interés en la vida del nasciturus es un interés estatal. Pero lo central es que ese interés ahora se puede hacer valer en cualquier momento del embarazo, con tal que no constituya un obstáculo insalvable al ejercicio del derecho al aborto antes de la viabilidad del feto. Expresado en términos de ponderación de intereses, el interés en la vida del nasciturus ha ganado en peso específico.

A la luz de esta comprensión de la evolución se podía levantar la cuestión de hasta dónde la viabilidad era un criterio necesario bajo Casey. Si el argumento central de la reformulación de Roe $v$. Wade en Casey era la necesidad de saivaguardar un ámbito para la decisión autónoma de la mujer, entonces es claro que ese ámbito queda salva- 
guardado con la solución del plazo dominante en Europa, es decir, la concesión de un plazo de tres meses para su ejercicio. Ese era, obviamente, el fin último perseguido por la legislación prohibitiva del empleo del método de $\mathrm{D} \& \mathrm{X}$. $\mathrm{Y}$, debe reconocerse, salvo por los argumentos de vaguedad y falta de contemplación de la indicación terapéutica, la aceptación de la constitucionalidad de la prohibición legal de un método abortivo empleado en momentos previos pero muy cercanos a la viabilidad, no era más que la consecuente implementación del principio que había marcado la redefinición de Roe v. Wade en Casey.

En este contexto, Carhart constituye un freno a esa tendencia evolutiva, testableciendo la consideración de la viabilidad como requisito para la aceptación constitucional de la decisión legislativa de asignar preponderancia a la vida del nasciturus por sobre la autonomía de la mujer.

\subsection{El estatus constitucional de los intereses en conflicto.}

Los intereses en conflicto en relación con la prohibición o autorización legal del aborto consentido son, por una parte, el interés en la preservación de la vida del nasciturus, y por otra parte, los intereses personalísimos de la mujer que se ven afectados por un embarazo y una maternidad no deseados. Más allá de esta descripción obvia, todo es controvertido.

(a) En relación con la vida del nasciturus, la primera interrogante se refiere a la condición precisa del interés en su protección desde el punto de vista de su rango jerárquico dentro del sistema de fuentes del ordenamiento. Conforme a la jurisprudencia del TS y de la CS, éste puede tener básicamente cuatro estatus, que en orden de menor a mayor peso específico son: (1) interés legítimo del Estado, (2) interés apremiante del Estado, (3) bien jurídico protegido u ordenado proteger por la Constitución, (4) derecho fundamental. En este esquema, el estatus de mayor peso respalda todas las consecuencias propias del estatus de menor peso, a las cuales agrega las que derivan del aumento de peso específico. Como se ha visto, la CS ha mantenido siempre la tesis de que el interés en la preservación de la vida del nasciturus a lo más puede alcanzar el estatus 2 a partir del momento de la viabilidad. EI TS, en cambio, atribuye a la vida del nasciturus el estatus 3 , pero con un peso específico equivalente al estatus 4 .

La segunda interrogante fundamental que plantea el análisis de este interés es la plausibilidad de una apreciación gradual de su peso específico. La constitución de un nuevo organismo con una identidad génetica propia, su primera diferenciación celular, su implantación en el endometrio, la expresión de su identidad genética en la consolidación de la diferenciación celular, el comienzo de la circulación sanguínea autónoma del feto, la aparición de los primero signos de funcionamiento de su sistema nervioso, la adquisición de un desarrollo que haría posible su sobrevivencia fuera 
del útero, el comienzo y el término del parto, son todos hitos de un desarrollo a los cuales se les puede asignar, y en algunos sistemas jurídicos de hecho se les asigna, importancia para la definición del estatus jurídico del conceptus o nasciturus.

El TS utiliza en sus sentencias el criterio del día catorce, es decir, la expresión de la identidad genética en la consolidación de la diferenciación celular, vinculándolo al criterio de la implantación, para afirmar el carácter indiscutido del merecimiento de protección constitucional. A partir de ese momento, sostiene que no es admisible diferenciación ulterior alguna. Su negativa es un evidente rechazo de la tesis de la CS, que atiende al momento de la viabilidad para reconocer al interés en la sobrevivencia del nasciturus un peso específico tal que pueda justificar el impedimento del ejercicio de un derecho constitucional. Con distintos resultados, ambos tribunales rechazan una apreciación gradual que relativice su criterio cronológico, en relación al cual establecen un criterio de todo (TS) o nada (CS). Pero, ¿no es inconsistente hacer una cisura en cl proceso de desarrollo prenatal, para luego negar la admisibilidad de un tratamiento más diferenciado? ${ }^{\text {?15 }}$

La respuesta a estas interrogantes se vincula a una de las cuestiones más básicas de la gramática profunda de la Constitución y el ordenamiento jurídico general, como es la definición de la condición de persona, en el sentido de titular de intereses fundamentales en condición de igualdad. Puesto que esta pregunta requiere la explicitación de los presupuestos metaéticos de la teoría de la justicia que se maneja como base de la interpretación constitucional (la más de las veces, en forma puramente intuitiva), su planteamiento suscita fundadas dudas acerca de la capacidad de rendimiento de ese esfuerzo teórico. Al fin y al cabo, si algo caracteriza al discurso jurídico es su falta de disposición a problematizar sus presupuestos.

Con todo, una discusión satisfactoria de la cuestión no puede eludir al menos un esclarecimiento de esos presupuestos. Gran parte de la discusión acerca del estatus del nasciturus procede de una discrepancia metaética radical, como es la que existe entre la justificación de los enunciados morales mediante su fundamentación en consideraciones ontológicas o en de racionalidad comunicativa. Por cierto, de esa clarificación no se deduce la respuesta a la pregunta de si una de ellas, y en su caso cuál de ellas, o si incluso ambas, son compatibles con las instituciones y prácticas morales y jurídicas elementales de la comunidad, de modo de poder justificar su plausibilidad como esquema de interpretación de la Constitución. Y por lo demás, tampoco se deduce de una respuesta afirmativa a esta última interrogante, la solución correcta del conflicto de intereses. Este es el auténtico error metodológico que debe ser evitado. Cualquier persona genuinamente interesada en buscar la mejor solución posible a este conflicto

115 Además, no puede perderse de vista que el desarrollo de la vida humana siempre ha estado sometido a un principio de gradación en la consideración de su merecimiento de protección penal. El comienzo o rérmino del parto es la cisura que marca el inicio del régimen de protección penal de la vida bajo el delito de homicidio, con una intensificación radical de la punibilidad y la penalidad. Esa es una diferencia cuya constitucionalidad no ha sido impugnada. 
debe abritse a la consideración de la relevancia del interés en la vida del nasciturus a pesar de negar su estatus de derecho fundamental, o a la relevancia comparable de los intereses de la mujer a pesar de afirmar el derecho a la vida del nasciturus, por otras razones, distintas de esta pueril geometría o física de los derechos subjetivos. La determinación del estatus de la vida del nasciturus es sin duda una pieza central para el correcto planteamiento del conflicto de intereses, pero no decisiva, en ninguno de los dos sentidos.

Ciertamente que un planteamiento como el de la CS prejuzga en un modo significativo al menos un resultado: si no se asigna a la vida del nasciturus un peso constitucional equiparable a un auténtico derecho de autonomía reproductiva de la mujer que incluye el aborto, no puede sino concluirse que la mujer debe gozar de libertad para practicar el aborto en una medida razonablemente oportuna para el ejercicio de ese derecho. Pero que el nasciturus no sea un titular del derecho subjetivo a la vida garantizado por la Constitución no significa sin más la irrelevancia de su vida para la Constitución. Y que haya que respetar una zona de libertad de la mujer frente a la intervención regulativa del Estado no significa sin más que esa zona tenga que alcanzar, en relación con la vida del nasciturus, los seis meses de embarazo. En ambos casos, se trata más bien de un non sequitur de la CS que de un razonamiento concluyente. Podrá gozar de la fuerza que le presta la doctrina del stare decisis, pero eso no es más que un argumento de autoridad.

A la inversa, del reconocimiento de un derecho a la vida del nasciturus no se deduce sin más la inexorabilidad de la prohibición penal del aborto, ni siquiera de una prohibición efectiva respecto de todas sus consecuencias jurídicas. Advertir esto es la gran lección que el TS ha dado a las demás jurisdicciones constitucionales, incluyendo a la propia CS. Esto, independientemente de los reparos que puedan merecer los términos precisos de su solución. La apreciación de la idoneidad de la pena de los intervinientes en el aborto, de la legítima defensa del nasciturus como tercero y de la nulidad de los contratos de prestación de servicios méditos abortivos como medios de protección efectiva de la vida del nasciturus es una exigencia de justicia política para una comunidad auténticamente interesada en proteger ese bien. Una comunidad que tenga auténticamente ese interés no puede ser ciega a las consecuencias de sus decisiones, es decir, no puede negarse por principio a verificar si esos medios son funcionales al logro del fin de protección de la norma constitucional.

(b) En relación con los intereses personalísimos de la mujer, que se ven afectados por un embarazo no deseado, el problema de su identificación no se refiere tanto a su vinculación al ámbito de protección de algún derecho constitucional sino a la determinación de su concreto peso específico frente al interés en la preservación de la vida del nasciturus. Es fácil reconocer que la integridad personal, la libertad general de acción y la vida privada (intimidad y derechos de la personalidad) de la mujer se ven alterados por el embarazo y la maternidad. Lo difícil es lograr una precisión concep- 
tual que sea capaz de expresar la determinación de la medida concreta en que esos intereses se ven afectados por un embarazo no deseado.

La dificultad anterior es abordable de dos maneras. Por una parte, se puede intentar configurar un derecho de autonomía consistente en el entrecruzamiento de las tres dimensiones personalísimas, unidas por la consideración de la autodeterminación del sentido y destino de la existencia personal. La subordinación de la maternidad a una prerrogativa de la mujer de participar en la fijación de su puesto en el cosmos es la base de la construcción de este derecho fundamental. Esta es la orientación seguida por la CS. La otra alternativa, seguida por el TS, consiste en mantener la idea de que en principio el embarazo es una afectación transitoria de cada uno de esos ámbitos de protección de derechos fundamentales, ${ }^{116}$ susceptible sin embargo de tranformarse en una afectación intensísima en casos excepcionales.

Una y otra opción responden a una comprensión del problema como una cuestión de ponderación de bienes jurídicos en un sentido estricto, por oposición al concepto más amplio de ponderación de intereses. ${ }^{117}$ En el marco de esa concepción restringida, las dimensiones fundamentales de la ponderación son la jerarquía del bien y la intensidad de su afectación. La disputa al interior de la jurisprudencia de la CS se refiere precisamente a la jerarquía del derecho a la autodeterminación reproductiva de la mujer. La opinión de minoría sostiene que se trata de un interés general de libertad, de escaso peso específico, mientras que la opinión de mayoria le asigna todo el peso de un derecho constitucional nominativamente reconocido. Por su parte, las dos tesis básicas del TS, esto es, la preponderancia de la vida del nasciturus por regla general y la preponderancia excepcional de los intereses personalísimos de la mujer, responden a la apreciación de la intensidad comparativa de la afectación como parámetro decisivo de la ponderación.

Como más adelante lo sugeriré, este planteamiento obvía el problema central de la ponderación de intereses que suscita el embarazo no deseado, y que se radica en la consideración de la autonomía personal como un límite a la ponderación de bienes, es decir, como una variable particularmente poderosa de la ponderación de intereses, irreconducible a la simple ponderación de bienes. En todo caso, es importante clarificar al menos en el nivel del texto constitucional el punto de apoyo de los intereses de la mujer embarazada.

Como ya se ha dicho, el interés más evidente es la salud o integridad física y psíquica. Que el embarazo trae consigo una alteración histológica y fisiológica del organismo

116 La identificación precisa de esos derechos, en rérminos generales, es una cuestión que depende de las particularidades del derecho constitucional positivo. En el derecho alemán, el derecho a la vida privada es un aspecto del derecho general a la personalidad, que a su vez es una concreción del decrecho al libre desarrollo de la personalidad (Art. 2-I de la Ley Fundamental), entendido como derecho de estatus (por contraposictón a su comprensión como libertad de acción), en virtud de su vincuiación al principio de la intangibiiidad de la dignidad humana.

117 Para esta contraposición en el ámbito de la causal de justificación del estado de necesidad, vid. Claus Roxin, Derecho Penal-Parte Geneтal, 1997, págs. 682 y ss. 
femenino, y que eso tiene también consecuencias psíquicas para la mujer, es algo indiscutible. Lo dudoso es cuál sea el peso específico de esta afectación, sin una consideración de la autonomía de la mujer, en todos los casos en que ella no rebasa el umbral propio de cualquier embarazo y parto. Parece más bien dudoso calificar médicamente al embarazo como una patología del organismo femenino; esto basta para advertir que desde esta pura perspectiva de la salud no puede tener mucho peso el interés de la mujer en evitar nueve meses de embarazo y un parto en comparación con la preservación de la vida del feto. Por cierto, el parto sigue siendo ciertamente un evento que conlleva riesgos para la mujer. ¿Pero puede asignarse a esos riesgos un peso particularmente relevante, a la vista del fenómeno de su progresiva reducción gracias al desarrollo de la medicina, que ha sido paralelo al aumento vertiginoso de toda otra clase de riesgos tranquilamente asumidos en la vida cotidiana? No es casual que la indicación médica o terapéutica tenga una tradición tan firmemente arraigada como caso excepcional. Lo que diferencia la situación de esta indicación del embarazo normal es precisamente el gatillamiento de un umbral relevante de riesgo para la salud o la vida de la mujer. Y esta diferencia es de tal magnitud que se puede hacer valer con total independencia del rol que le sea asignado como principio general a la autonomia de la mujer, tanto bajo la CS como bajo el TS.

La libertad general de acción es otro interés obviamente afectado por un embarazo y la maternidad subsecuente. Pero éste es quizás el interés constitucional con menor peso específico de todos. Para que el interés general de libertad adquiera un peso específico mayor es necesario concretarlo. En el lenguaje de la teoría (metafórica) de las esferas de libertad, es necesario advertir que la libertad de embarazarse o abortar pertenece al ámbito más personalísimo, y por lo tanto libérrimo, de ese interés. Este proceso de concreción argumentativa es el correlato del proceso que debe darse asimismo en el concepto de la privacidad, intimidad o vida privada como interés constitucional. En este otro contexto, la concreción opera desde un derecho de exclusión comunicacional o de control de contenidos informativos hacia un derecho de autonomía. No es casual, pues, que el derecho a la autonomía reproductiva o bioética se pueda construir a partir de cualquiera de los dos intereses, la libertad de acción (TS) o la privacidad (CS), con tal que su reconocimiento se produzca mediante una línes jurisprudencial que evolucione hacia el otro interés correlativo. Una de estas dos construcciones conceptuales es necesaria para dar un apoyo constitucional a los argumentos basados en la autonomía. Pero de la aceptación de cualquiera de ellas no se deduce sin más su peso específico, en particular frente al interés en la preservación de la vida del nasciturus, si es que se lo considera un interés constitucionalmente relevante. La decisión de este conflicto requiere una consideración adicional, sobre la que volveré más adelante. 


\subsection{Consecuencias de los resultados de la ponderación de intereses.}

Si el resultado de la ponderación de intereses en conflicto favorece a la autonomía reproductiva de la mujer, las consecuencias mínimas son claras. El Estado debe respetar ese derecho en un margen suficiente para no afectarlo en su esencia. Esto significa que la Constitución concede a la mujer una autorización para optar por el embarazo o el aborto, que no puede ser obstaculizada por el legistador, la administración ni la judicatura, en el sentido de que la última decisión o la responsabilidad última debe quedar en manos de la mujer. A la luz del derecho comparado, se puede conjeturar que el plazo de tres meses desde la implantación o la concepción es el mínimo indispensable para que esa autorización pueda hacerse valer oportunamente. La pregunta de si la sujeción de la mujer a un procedimiento de consejo forzoso, con plazo de espera, así como la exigencia de autorización conyugal o paterna, con autorización judicial subsidiaria, son restricciones admisibles bajo esta ponderación de intereses tiene un principio de respuesta favorable en la evolución de la jurisprudencia de la CS. Por cierto, bajo este planteamiento de la ponderación de intereses, estas restricciones no se deducen de la Constitución. Son lisa y llanamente restricciones legales no inconstitucionales.

Mucho menos claras son las consecuencias de un resultado de la ponderación de intereses favorable a la vida del nasciturus. Con todo, a la luz de la jurisprudencia del TS se puede esbozar algunos lineamientos generales.

En primer lugar, debería darse por descontado que la configuración de un régimen de indicaciones como causas de justificación tiene apoyo constitucional suficiente, a pesar de la preponderancia de la vida del nasciturus. Si el concepto de inexigibilidad es o no la categoría más adecuada para fundamentar la conformidad a derecho del aborto practicado en esas situaciones excepcionales, esa es una interrogante que puede quedar abierta. Lo concluyente es que el resultado de la ponderación puede variar, según las circunstancias. Esto obedece, tanto al hecho de que la ponderación incorpora como variable al menos la intensidad comparativa de la afectación además de la jerarquía de bienes en conflicto, como asimismo al hecho de que el aborto consiste en una reacción defensiva de la mujer, por lo que se atenúan las exigencias de preponderancia de! bien protegido frente al bien a afectado. ${ }^{118}$

En segundo lugat, debería ser indiscutible que un deber de protección no implica sin más un deber de punición. Incluso en el caso de un deber de protección de un bien de máxima jerarquía frente a ataques que lo destruyen irreparablemente, la derivación de un mandato de punición a partir de un mandato de protección tropieza con dos obstáculos formidables. El primero, no aceptado por la mayoría del TS, es la distor-

I 8 No es que la mujer actúe en legíima defensa contra el embrión o feto: éste no es un ser capaz de acción, por lo que no puede incurrir en una agresión ilegitima, que es presupuesto de la legítima defensa. La mujer actúa amparada por un estado de necesidad defensivo, que puede adquirir el carácter de justificación. Acerca de las diferencias entre el estado de necesidad justificante defensivo y el agresivo para la ponderación de intereses, vid. Claus Roxin, op. cit., supra, nota 117, págs. 705-712. 
sión del sentido y función de los derechos fundamentales, que de constitujr límites al ius puniendi pasan a servir como fuente de impulso de su ejercicio. Ese es un paso que una jurisprudencia constitucional frel al origen histórico y a la finalidad garantista de los derechos fundamentales debe cuidarse de dar. El segundo, que constituye la médula de la postura de la mayoría del TS, es que aun aceptando la derivación de un mandato de punición, la pena nunca es fin en sí misma; desde la perspectiva de la Constitución, la pena es un medio para realizar ciertos fines. En tal función, la pena no está exenta de una revisión de su idoneidad como medio efectivo de protección, sino por el contrario rigurosamente sometida a ella. Y la evidencia empirica puede corroborar la tesis de que la peculiaridad del aborto hace que la pena fracase rotundamente como medio de protección de la vida del nasciturus.

La cuestión más difícil que plantea la solución del conflicto de interés en favor de la vida del nasciturus comienza recién en este punto, cuando se acepta la inadecuación de la pena como medio institucional de protección. Quien se tome en serio el debet constitucional de protección de la vida del nasciturus no puede quedar satisfecho con la mera despenalización como consecuencia. Tratándose del aborto no es aplicable el ejercicio rutinario de la política criminal respetuosa del principio de la última ratio. En un tal contexto constitucional, la vida del nasciturus no se encuentra en una situación semejante a la posesión de los inmuebles, para cuya protección basta con la posesión inscrita, el regimen registral y los mecanismos del procedimiento civil. En este punto la postura del TS no parece susceptible de refutación. Bajo una Constitución que impone un deber de protección de la vida del nasciturus se puede prescindir de la pena del aborto, si y solo si se implementa sustitutivamente otro medio de protección efectiva. Abierta queda, ciertamente, la pregunta acerca de la medida de lo satisfactorio como protección sustitutiva, particularmente tomando en consideración la inadecuación de un sistema de protección puramente punitivo y de una purribilidad primariamente simbólica. Pero en todo caso, un grado importante de intensificación de la protección a la vida del nasciturus dispensada a través de políticas sociales es una condición necesaria de la prescindencia de la protección penal.

La transformación de la protección penal en una protección social es una tarea que solo puede ser posible si se cuenta con la colaboración del Estado, en la legislacióny la administración. Esta es una exigencia difícil de ser satisfecha. La experiencia alemana es en este sentido bastante atípica, ya que presenta el fenómeno poco usual de un legislador y un tribunal constitucional que coinciden en la representación de los fines, en el diagnóstico de la inadecuación de los medios hasta entonces empleados y en los aspectos esenciales del cambio estimado como correcto. Esto suscita la interrogante de la plausibilidad que pueda tener un alegato en contra de un sistema de protección primariamente penal desde una posición de minoría. Suponiendo que esa minoría pueda producir evidencia incontrarrestable acerca de la inidoneidad de la punición del aborto consentido, y que la mayoría democrática decida no asignar relevancia a 
esa evidencia, insistiendo en la prohibición penal como una cuestión de principio, ¿podría efectuarse un planteamiento constitucional? Esto no es más que una aplicación concreta de la pregunta más elemental acerca de la operatividad judicial de la doctrina de los deberes constitucionales de protección de derechos (o bienes) fundamentales. Al igual que la doctrina de las prohibiciones de afectación, esta doctrina es funcional como bloqueo de iniciativas legislativas, en este caso, de desprotección. Pero en función de su propia dinámica normativa los deberes de protección tendrían que aspirar a ser operativos como impulso de iniciativas legislativas. :Cómo podría ser eso institucionalmente posible, sin el concurso de la voluntad legislativa? Con ocasión de su segunda sentencia sobre la interrupción del embarazo, el TS llevó al límite el ejercicio de su potestad normativa para la dictación de la reglamentación de ejecución de sus decisiones. Pero no es usual que los órganos que ejercen la jurisdicción constitucional detenten esa potestad normativa. $Y$ sin ello, ¿cómo podría hacerse efectivo el contenido de un mandato de protección?

Finalmente, la transformación de un sistema de protección penal en un sistema de protección social exige encarar el problema de la antjjuridicidad del aborto consentido, fuera de los casos excepcionales de las indicaciones. Este es un problema límite. La despenalización del aborto consentido sin su autorización legal, es decir, sin establecerse al mismo tiempo una causa de exclusión de la ilicitud de alcance general para el aborto consentido practicado en las condiciones previstas por la ley, produce una situación altamente insatisfactoria. La posibilidad de que terceros ejerzan legítima defensa en favor del feto, la nulidad de los contratos de prestación de servicios médicos abortivos y la imposibilidad de obtener prestaciones de salud previsional o de seguridad social para la práctica del aborto expone a la mujer a serios riesgos, y además es disfuncional a un sistema de protección del nasciturus orientado a la persuasión de la mujer.

Una vez más se revela que el problema constitucional de la regulación del aborto no es un mero problema de límites al ejercicio del ius puniendi. Es un error creer que las cuestiones que suscita la regulación del aborto consentido son puramente políticocriminales. En esto debe concederse también la corrección del punto de vista fundamental del TS: si la Constitución ordena la protección del nasciturus, entonces lo que exige es un concepto global de protección. Lo problemático de su posición es la tesis de la necesidad constitucional de la prohibición legal pero no penal del aborto consentido.

¿Es necesaria esa prohibición? Si se sostiene respecto de un orden constitucional determinado que en él se encuentra una prohibición general de atentar contra el nasciturus cuyo destinatario es cualquiera, entonces se tiene que afirmar en principio la inconstitucionalidad de una norma permisiva legal. Pues el derecho infraconstitucional 
no puede válidamente contener normas contradictorias con las normas constitucionales, como lo sería una norma que establezca un permiso. ${ }^{119}$

La idea de que las normas sobre derechos fundamentales establecen prohibiciones de afectación correlativas respecto de cualquiera es una idea asentada en el derecho constitucional chileno, pero es una idea ajena al derecho constitucional comparado. $\mathrm{Ni}$ en los Estados Unidos ni en Alemania sería admisible semejante concepción de los efectos jurídicos de las normas sobre derechos fundamentales. ${ }^{120}$ Por ello es que el TS elabora su teoría sobre la necesidad constitucional de la prohibición legal del aborto desde una perspectiva funcional: la prohibición legal es un elemento indispensable de la protección estatal del nasciturus.

¿Pero por qué es eso así, desde una perspectiva funcional? Si las consecuencias más obvias de la prohibición son disfuncionales a la efectividad de la protección del nasciturus en un concepto preventivo, como lo reconoce el propio TS, ¿̨cuál puede ser la base de la necesidad de esa prohibición? La respuesta del TS es muy peculiar: no se puede prescindir del efecto de orientación social favorable al nasciturus que produce la existencia de la prohibición. La significación cultural se transforma aquí en la razón de ser de la norma jurídica. ${ }^{121}$ Es como si la Constitución exigiera del Estado la afirmación institucional de una norma de comportamiento de la moral social, que mantiene su carácter de tal pese a esa afirmación estatal. El resultado es en verdad tan peculiar, que difícilmente podría admitirse la validez de una decisión del legislador de formular esa interpretación, efectuando por sí mismo esa distinción. Se requiere un órgano que posea al mismo tiempo poder final de aplicación de la Constitución y potestad normativa, como lo es el TS, para poder introducir una solución semejante en el ordenamiento jurídico.

\subsection{La autonomía personal como limite a la ponderación de bienes.}

La representación usual del razonamiento de la CS y del TS lo concibe como una ponderación de bienes. Esa representación se ha seguido también en las páginas anteriores. En semejante contexto, la jerarquía de cada bien y la intensidad comparativa

119 Distinto sería el caso de una norma derogatoria de una norma legal prohibitiva. Puesto que el efecto de una norma legal prohibiriva puede ser considerado redundante si existe una norma constitucional prohibitiva, ia eliminación de la redundancia no introduciría un cambio en el sistema. Todo depende de la consideración de los efectos de una y otra prohibición. Todo esto se entiende, por cierto, al margen de las normas configuradoras de causas de justificación excepcionales, cuya constitucionalidad no puede ponerse seriamente en duda.

120 Cierto es que la doctrina alemana ha elaborado la categorfa de la Drittwirkung (= efecto para tercero), o efecto reflejo de los derechos fundamentales en las relaciones entre particulares, que es la consecuencia principal de la idea del orden valorativo objetivo (supra, nota 85 ). Pero ese efecto no es equiparable sin más a la idea de un efecto directo entre particulares, que es lo que en Chile se acepta sin mayor cuestionamiento.

I21 No se puede descartar que detrás de esta tesis del TS esté el fantasma de Roe $\nu$. Wade. El hecho que el TS haya adoptado sus decisiones justamente después de las decisiones cruciales de la CS es un antecedente importante para el análisis del contexto de descubrimiento de su jurisprudencia. El rechazo a Roe $v$ Wade es explícito en la sentencia de 1975. En la sentencia de 1993, la exigencia de que el legislador exprese la antijuridicidad del aborto es ia única diferencia sustancial entre el TS y Casey en lo que respecta a sus resultados. 
de su afectación son las variables fundamentales de la ponderación. La CS resuelve el conflicto asignando preponderancia a la autonomía reproductiva de la mujer en virtud de una consideración de jerarquía: el interés de la mujer es un derecho constitucional específico, el interés en la protección de la vida potencial es un interés estatal que sólo resulta apremiante a partir del momento de la viabilidad del feto. En otras palabras, antes de la viabilidad del feto, el interés en la protección de su vida tiene un rango manifiestamente inferior al de la autonomía de la mujer, por lo que la Constitución ordena permitir el aborto. El TS, por su parte, considera que en circunstancias normales el conflicto debe decidirse en favor de la vida del nasciturus, porque es un interés constitucional fundamental, como mínimo equiparable a la autonomía de la mujer, $y$ porque el aborto es exponencialmente más grave que el embarazo desde el punto de vista del grado comparativo de la afectación del interés respectivo, por lo que la Constitución ordena prohibir el aborto. Cuando por la concurrencia de circunstancias excepcionales aumenta la intensidad de la afectación de la autonomía de la mujer, la ponderación cambia, y el orden constitucional ordena o permite la autorización del aborto.

Un razonamiento de esta naturaleza concentra la discusión en la determinación del estatus del bien afectado. De aquí que la cuestión de si la vida del nasciturus es o no un interés constitucional con un peso específico equiparable a los derechos fundamentales sea el punto central del debate. En un contexto de estas características, la idea del TS de la inexigibilidad como fundamento de una reversión del resultado de la ponderación de intereses resulta necesitada de explicación. Pues, jcómo podría el aumento de la intensidad de la afectación de bienes tan inferiores a la vida de un individuo alcanzar un peso específico equiparable a la destrucción total e irreversible de esa vida? La consideración del conflicto como un estado de necesidad defensivo a lo más elimina la necesidad de preponderancia esencial del interés personalísimo de la mujer. Eso basta para fundamentar la indicación médica, cuando hay un serio peligro para la vida o de un daño grave e irreparable a la integridad física o psíquica de la mujer. Pero los otros supuestos de inexigibilidad que según el TS dan o pueden dar lugar a causas de justificación del aborto (indicaciones) no parecen sencillos de fundamentar mediante una ponderación de bienes. En particular, la indicación criminológica y la indicación social (estado de necesidad general) descansan sobre la afectación de derechos de autonomía (libertad de acción, personalidad, vida privada) cuya intensidad difícilmente puede equipararse con la intensidad de la muerte. En realidad, la idea de la inexigibilidad no es tanto la expresión de un resultado de ponderación de bienes, como un principio adicional que debe ser tomado en consideración, y que marca un límite a la ponderación posible.

Esta función del principio de la autonomía no es desconocida en la teoría general del delito. En el matco de la ponderación de intereses que es propia del estado de necesidad, se reconoce que el principio de la ponderación de bienes encuentra en la autonomía del afectado un límite a su capacidad de fundamentación de la conformidad a 
derecho de esa afectación. ${ }^{122}$ La versión extrema de este reconocimiento declara injustificable cualquier afectación del cuerpo de una persona con el fin de evitar un riesgo de muerte o de lesión grave de otro. Conforme a este planteamiento, el principio de la autonomía es una restricción no sujeta a su vez a ponderación. La versión moderada acepta que el principio de autonomía sea integrado a la argumentación de ponderación, y que por lo tanto pueda ser contrarrestado por una enorme preponderancia del bien de protección. Así, por ejemplo, una transfusión de sangre que no acarrea mayores complicaciones al afectado puede ser excepcionalmente realizada contra su voluntad, si es que ese es el único medio disponible para salvar la vida de una persona que padece una hemorragia o anemia. Pero forzar a una persona a permanecer nueve meses conectado a un sistema de diálisis sanguínea de otro está claramente más allá del límite de las afectaciones permisibles, aunque sea el único medio de salvar la vida del beneficiado. ${ }^{23}$

¿Se encuentra la mujer con un embarazo no deseado en esa situación? Desde el punto de vista del principio de la autonomía, es claro que nadie puede ser obligado por el Estado a asumir respecto de cualquier individuo ya nacido obligaciones y cargas de la magnitud que el embarazo trae consigo. ¿Qué hace que la situación de la mujer embarazada respecto del embrión o feto sea distinta? La apelación al derecho a la vida del nasciturus es aquí impotente. Nadie duda que en el caso anterior el tercero tiene derecho a la vida, y de ello nadie deduce un deber de tolerar en su favor esa afectación del propio cuerpo, la propia vida privada y la propia libertad. Esta pregunta fue planteada en el debate de la filosofía moral norteamericana hace treinta años por Judith Jarvis Thompson con su célebre ejemplo del violinista, ${ }^{124}$ y sigue siendo el corazón del problema de la prohibición legal del aborto consentido, así como la clave para descifrar las diferencias que separan a la CS del TS.

La posición de la CS admite ser reinterpretada en términos de la pregunta anterior. Su respuesta es: nada diferencia la situación de la mujer embarazada. La defensa de la deferencia a la autonomía de la mujer se expresa en Roe $v$. Wade como el reconocimiento de un derecho constitucional nominativo, y en Casey como la exigencia de dejar a la decisión de la mujer la última palabra. El hecho de la naturaleza de que la vida humana en su estado inicial de desarrollo sea una vida dependiente de un organismo femenino no puede hacerse valer como argumento para compensar el debido

122 Claus Roxin, op. cit., supra, nota 117 , págs. 628-630.

123 Roxin, loc cit.

I24 A Defense of Abortion, en: Philosophy \& Public Affairs, Vol. I (1971), págs. 47-66. El artículo ha sida recogido en múltiples selecciones posteriores, dos de las cuales han sido traducidas al español, Ronald Dworkin (ed), Filosofia del Derecho, México, 1980, y v.v.a.a., Debate sobre el aborto: cinco ensayos de filosofia moral, Madrid, 1983. En vez de las particularidades que todean este caso, tal como lo plantea la autora, se lo debería configurr del modo más simple y pertinente: Sin que una mujer lo sepa (- encontrándose en estado de inconsciencia), $x$ toma la decisión de salvar la vida de su hijo ya nacido pero enfermo, quien necesita una diálisis de nueve meses it duración, mediante la anexión del cuerpo de la mujer al aparato de diálisis que mantiene con vida al hijo. És vuelve en sí y se encuentra en ese estado: jeitene una obligación constitucional de permanecer en tal condición durante nueve meses? 
respeto a la autonomía de la mujer. Su estatus como persona lo impide. La premisa del TS es justamente la inversa: la dependencia es el modo de existencia natural de los seres humanos en su vida temprana, por lo que su protección exige oponer a la mujer el deber de tolerar esa vida en su situación vital y llevarla hasta el grado de desarrollo que le permita la independencia. Y aquí es donde interviene la concepción de las circunstancias excepcionales de inexigibilidad: cuando la situación en que se encuentran el embrión o feto y la mujer ya no es una de dependencia natural, sino que impone a la mujer cargas que sobrepasan esa medida, entonces el deber de sobrellevar la situación vital del embrión o feto deja de ser exigible. La inexigibilidad se produce cuando se sobrepasa el umbral impuesto por la naturaleza. La diferencia entre la CS y el TS, por lo tanto, puede ser considerada como gradual o relativa: uno y otro tribunal difieren en el criterio que utilizan para reconocer la autonomía de la mujer como límite a los deberes de toletar la afectación de bienes personalísimos para provecho ajeno. El embarazo es una afectación que excede ese límite, según la CS. Según el TS, ese límite se excede solamente cuando concurren circunstancias excepcionales que hacen del embarazo una carga más pesada que la que importa por naturaléza.

La auténtica diferencia entre una y otra posición se encuentra, pues, en la negación y la afirmación para la mujer embarazada de un deber de tolerancia del embarazo y de garante de su progresión hasta el parto, fundada en la condición natural de vida del embrión o feto. El debate acerca de la existencia o inexistencia de uno u otro derecho subjetivo simplemente cubre los flancos de esta pregunta, para poder darla por resuelta de un modo técnicamente más operativo.

Esta es una pregunta para la justicia política. Es claro que el origen del problema se encuentra en la peculiaridad de la condición existencial de los seres humanos, compartida con los demás mamíferos, en su etapa más temprana de desarrollo. Es claro asimismo que esta situación no puede resolverse sin hacer de ella, o bien una desgracia natural para el embrión o feto que tiene esa existencia peculiar, o una carga para la mujer que se ha visto involucrada en esa situación existencial del embrión o feto. ¿Qué razones tenemos para atribuir esa carga a la mujer? ¿Por qué el embrión o feto tiene respecto de su condición natural de ser dependiente un tratamiento privilegiado en comparación con el que tendría en circunstancias semejantes un ser humano nacido?

Frente a la autonomía de la mujer, la pregunta correcta no es, pues, si el nasciturus tiene o no el mismo estatus que el nacido. La pregunta es si existen razones para justificar lo que de otro modo serían consecuencias de algo inaceptable: que tuviera un estatus superior. 